\title{
High-resolution solid state NMR experiments for the characterization of calcium phosphate biomaterials and biominerals
}

\author{
Frédérique Pourpoint, Cristina Coelho Diogo, Christel Gervais, and Christian Bonhomme \\ Laboratoire Chimie de la Matière Condensée de Paris, UMR CNRS 7574, UPMC Université Paris 06, \\ Collège de France, 75231 Paris cedex 05, France \\ Franck Fayon \\ CEMHTI, CNRS UPR 3079, 45071 Orléans cedex 2, France \\ Sara Laurencin Dalicieux, Isabelle Gennero, and Jean-Pierre Salles \\ INSERM Unité 563 (Centre de Physiopathologie de Toulouse Purpan), Université Paul-Sabatier, Hôpital Purpan, \\ CHU de Toulouse, 31059 Toulouse cedex 9, France
}

Andrew P. Howes, Ray Dupree, John V. Hanna, and Mark E. Smith

Department of Physics, University of Warwick, CV4 7AL Coventry, UK

Francesco Mauri

Laboratoire de Minéralogie Cristallographie UMR CNRS 7590, UPMC Université Paris 06, France

Gilles Guerrero, P. Hubert Mutin, and Danielle Laurencin ${ }^{\text {a) }}$

Institut Charles Gerhardt de Montpellier, UMR 5253, CNRS UM2 UM1 ENSCM, CC 1701

Université de Montpellier 2, 34095 Montpellier cedex 5, France

(Received 10 April 2011; accepted 22 July 2011)

\begin{abstract}
Calcium phosphates form a vast family of biominerals, which have attracted much attention in fields like biology, medicine, and materials science, to name a few. Solid state Nuclear Magnetic Resonance (NMR) is one of the few techniques capable of providing information about their structure at the atomic level. Here, examples of recent advances of solid state NMR techniques are given to demonstrate their suitability to characterize in detail synthetic and biological calcium phosphates. Examples of high-resolution ${ }^{31} \mathrm{P},{ }^{1} \mathrm{H}$ (and $\left.{ }^{17} \mathrm{O}\right)$, solid state NMR experiments of a ${ }^{17} \mathrm{O}$-enriched monocalcium phosphate monohydrate-monetite mixture and of a mouse tooth are presented. In both cases, the advantage of performing fast Magic Angle Spinning NMR experiments at high magnetic fields is emphasized, notably because it allows very small volumes of sample to be analyzed.
\end{abstract}

\section{INTRODUCTION}

Calcium phosphates form a vast family of biominerals, which are present in a large number of biological tissues. ${ }^{1-5}$ Hydroxyapatite (HA) is the most studied calcium phosphate phase because it is the main mineral component of bone and teeth. Its composition differs from that of stoichiometric HA $\left[\mathrm{Ca}_{10}\left(\mathrm{PO}_{4}\right)_{6}(\mathrm{OH})_{2}\right]$ due to the presence of several ionic substitutions in the HA lattice, such as $\mathrm{CO}_{3}{ }^{2-}, \mathrm{HPO}_{4}{ }^{2-}, \mathrm{Na}^{+}$, and $\mathrm{Mg}^{2+}$. Brushite (dicalcium phosphate dihydrate, $\mathrm{CaHPO}_{4} \cdot 2 \mathrm{H}_{2} \mathrm{O}$ ) and octacalciumphosphate $\left[\mathrm{OCP}, \mathrm{Ca}_{8}\left(\mathrm{HPO}_{4}\right)_{2}\left(\mathrm{PO}_{4}\right)_{4} .5 \mathrm{H}_{2} \mathrm{O}\right]$ phases have been observed in pathological calcifications like dental calculi and urinary stones. ${ }^{2}$ Substituted $\beta-\mathrm{Ca}_{3}\left(\mathrm{PO}_{4}\right)_{2}$ $(\beta-\mathrm{TCP})$ can also be present in some forms of dental calculi and salivary stones, while calcium pyrophosphate

\footnotetext{
a) Address all correspondence to this author. e-mail: danielle.laurencin@univ-montp2.fr

This paper has been selected as an Invited Feature Paper.

DOI: $10.1557 /$ jmr.2011.250
}

dihydrate $\left(\mathrm{Ca}_{2} \mathrm{P}_{2} \mathrm{O}_{7} .2 \mathrm{H}_{2} \mathrm{O}\right)$ crystals can form in connective tissues and joints, leading to diseases like pseudo-gout (also referred to as Calcium Pyrophosphate Deposition Disease) and acute arthritis. In addition to these crystalline calcium phosphates, another important phase is amorphous calcium phosphate (ACP, $\left.\mathrm{Ca}_{x} \mathrm{H}_{y}\left(\mathrm{PO}_{4}\right)_{z} \cdot n \mathrm{H}_{2} \mathrm{O}\right)$. ACP is generally unstable in physiological conditions, where it tends to transform into crystalline HA. Although details of its structure have not yet been fully elucidated, experiments carried out in vitro suggest that there are several compositions for ACP, depending on the precipitation conditions, and notably on the $\mathrm{pH}$ and the supersaturation of the calcium and phosphate ions in solution. ${ }^{5}$

Because of the biological importance of calcium phosphates, many research teams have endeavored to understand their formation and stability under physiological conditions, one of the main objectives being to develop efficient calcium phosphate-based biomaterials or cements for bone tissue regeneration. In this context, a particular effort was made in trying to describe the structure of these biological phases and compare it with synthetic calcium phosphate analogues. 
Several analytical techniques have thus been used, such as $\mathrm{x}$-ray diffraction (XRD), ${ }^{6-8}$ electron microscopy, ${ }^{9,10} \mathrm{IR}$ and Raman spectroscopies, ${ }^{6,11-16} \mathrm{Ca}$ K-edge $\mathrm{X}$-ray absorption spectroscopy, ${ }^{17-19}$ and solid state Nuclear Magnetic Resonance (NMR).

Solid state NMR is a technique which is well adapted to the study of the structure of biological and synthetic calcium phosphate minerals at the atomic level. ${ }^{17,20-40}$ Indeed, the four main nuclei present in calcium phosphates are calcium, phosphorous, oxygen, and hydrogen, each of which has an isotope that can be studied by NMR (Table I). As detailed below, most of the solid state NMR investigations reported so far concern ${ }^{1} \mathrm{H}$ and ${ }^{31} \mathrm{P}$, as these are two spin $1 / 2$ isotopes of high natural abundance and receptivity. In contrast, ${ }^{43} \mathrm{Ca}$ and ${ }^{17} \mathrm{O}$ are quadrupolar nuclei (which means that they have a nuclear spin $I>1 / 2$ and a quadrupole moment $Q$ ), and their natural abundance is low. It is only more recently that they have started to be used for the characterization of calcium phosphates or bone, notably because high-field magnets are needed to obtain high-resolution spectra.

Early ${ }^{31} \mathrm{P}$ NMR studies of calcium phosphates and bone used mainly Magic Angle Spinning (MAS) single-pulse experiments and ${ }^{1} \mathrm{H} \rightarrow{ }^{31} \mathrm{P}$ cross-polarization $(\mathrm{CP})$ techniques. The comparison of single-pulse and ${ }^{1} \mathrm{H} \rightarrow{ }^{31} \mathrm{P}$ CPMAS spectra can help distinguish different phosphate environments, ${ }^{20,33,34}$ as only the phosphorous atoms close to protons appear in the latter spectra. Important structural information can be thus derived, and further insight into ${ }^{1} \mathrm{H}^{31} \mathrm{P}$ proximities can be obtained by recording a series of $1 \mathrm{D}$ CPMAS experiments, ${ }^{23,25}$ and/or by recording two dimensional (2D) ${ }^{1} \mathrm{H}^{-31} \mathrm{P}$ heteronuclear-correlation (HETCOR) spectra, which show which phosphates are close to which hydrogen atoms $\left(\mathrm{OH}, \mathrm{P}-\mathrm{OH}\right.$ or $\left.\mathrm{H}_{2} \mathrm{O}\right)$ in the material. $^{20,22,35,38}$ For more complex species, experiments based on ${ }^{31} \mathrm{P}_{-}{ }^{31} \mathrm{P}$ dipolar couplings and $\mathrm{J}$-couplings (if $\mathrm{P}-$ $\mathrm{O}-\mathrm{P}$ bonds are present) can be carried out, ${ }^{21,36,37}$ as recently illustrated in the case of OCP. ${ }^{37}$

High-resolution ${ }^{1} \mathrm{H}$ solid state NMR is generally more difficult to carry out than ${ }^{31} \mathrm{P}$ NMR because of strong homonuclear ${ }^{1} \mathrm{H}-{ }^{1} \mathrm{H}$ dipolar couplings. Nevertheless, the signals from different hydrogen atoms $(\mathrm{OH}, \mathrm{P}-\mathrm{OH}$, or $\mathrm{H}_{2} \mathrm{O}$ ) present in synthetic calcium phosphate phases can be observed. ${ }^{20,21}$ In the case of bone, more complex spectra are obtained because of the presence of additional ${ }^{1} \mathrm{H}$ signals due to the organic collageneous matrix. In this case, the ${ }^{1} \mathrm{H}$ peaks coming from the mineral phase of bone

TABLE I. Main NMR isotopes present in calcium phosphates.

\begin{tabular}{lcccc}
\hline \hline Isotope & Spin & $\begin{array}{c}\text { Natural } \\
\text { abundance }(\%)\end{array}$ & $\begin{array}{c}\text { Receptivity } \\
\text { (rel. to }{ }^{13} \mathrm{C} \text { ) }\end{array}$ & $\begin{array}{c}\text { Larmor frequency at } \\
14.1 \mathrm{~T} \text { (in MHz) }\end{array}$ \\
\hline${ }^{1} \mathrm{H}$ & $1 / 2$ & 99.98 & $5.87 \times 10^{3}$ & 600.1 \\
${ }^{31} \mathrm{P}$ & $1 / 2$ & 100 & $3.91 \times 10^{2}$ & 242.9 \\
${ }^{17} \mathrm{O}$ & $5 / 2$ & 0.037 & $6.50 \times 10^{-2}$ & 81.4 \\
${ }^{43} \mathrm{Ca}$ & $7 / 2$ & 0.145 & $5.10 \times 10^{-2}$ & 40.4 \\
\hline \hline
\end{tabular}

can be picked out by recording a $2 \mathrm{D}{ }^{1} \mathrm{H}^{31} \mathrm{P}$ HETCOR spectrum ${ }^{22,35}$ or a $1 \mathrm{D}^{31} \mathrm{P} \rightarrow{ }^{1} \mathrm{H}$ CPMAS spectrum. ${ }^{29,39}$

${ }^{43} \mathrm{Ca}$ solid state NMR is intrinsically difficult: calcium-43 is a spin $7 / 2$ nucleus with a low resonance frequency (it is referred to as a low-gamma nucleus) and a very low natural abundance (Table I). Nevertheless, we have recently shown that ${ }^{43} \mathrm{Ca}$ NMR spectra of calcium phosphates and bone can be recorded at natural abundance, ${ }^{17,31,32,40}$ using large volume rotors and signal-enhancement schemes specific to quadrupolar nuclei, most helpfully in combination with high magnetic fields. Calcium- 43 being a quadrupolar nucleus, the position and lineshape of a ${ }^{43} \mathrm{Ca}$ NMR signal will vary with the magnetic field used for the measurement due to variations of the second order quadrupolar shift and broadening (the latter being inversely proportional to the magnetic field). In MAS, the lineshape mainly depends on three parameters, the isotropic chemical shift $\delta_{\text {iso }}$ and the quadrupolar parameters $\eta_{\mathrm{Q}}$ and $\mathrm{C}_{\mathrm{Q}}$. By recording the ${ }^{43} \mathrm{Ca}$ NMR spectra of a calcium phosphate sample at different magnetic fields, it is possible to extract these NMR parameters, and notably an isotropic chemical shift $\delta_{\text {iso }},{ }^{17,31,32}$ which can provide information on the average $\mathrm{Ca}$.. .O bond distance. ${ }^{32}$

Oxygen-17 is another difficult quadrupolar nucleus, with a very low sensitivity. However, it is a key nucleus for the characterization of materials, as oxygen-17 NMR parameters can provide very valuable structural information. ${ }^{21,41,42}$ Because of the very low sensitivity of oxygen-17 NMR, very few ${ }^{17} \mathrm{O}$ NMR spectra of calcium phosphates have been reported so far, and concerning the $\mathrm{HA}$ phase, only the spectrum of a HA sample ${ }^{17} \mathrm{O}$-enriched in only the phosphate position has been reported. ${ }^{43}$

Due to the complexity of materials like calcium phosphates, solid state NMR spectra can also be particularly complex, especially in biological materials like bone, where distributions in local environments can lead to broader NMR signals. Two key points are thus essential to interpret the spectra: (i) obtaining high-resolution solid state NMR spectra of these materials, (ii) developing means to help assign the signals observed and explain the nature of the chemical environment of the nuclei. In the latter case, it has been demonstrated over the past few years that the combination of computational modeling and density-functional theory (DFT) calculations of NMR parameters [using the Gauge-Including Projector Augmented Wave method (GIPAW) $]^{44}$ can be used to help interpret solid state NMR spectra, including for calcium phosphate phases. ${ }^{21,32,36,40,45}$ In particular, the experimental ${ }^{31} \mathrm{P},{ }^{1} \mathrm{H}$, and ${ }^{43} \mathrm{Ca}$ NMR spectra of crystalline calcium phosphates of known structure have been shown to be in very good agreement with the calculated NMR data.

The purpose of this article is to show two examples of recent progress made in the field of solid state NMR, which can help in the interpretation of the structure of complex calcium-phosphate biomaterials, whether they 
are synthetic (as is the case for calcium-phosphate phases used for tissue engineering) or natural. The first concerns a high-resolution ${ }^{17} \mathrm{O},{ }^{31} \mathrm{P}$, and ${ }^{1} \mathrm{H}$ NMR study of a synthetic mixture of monocalcium phosphate monohydrate [MCPM, $\left.\mathrm{Ca}\left(\mathrm{H}_{2} \mathrm{PO}_{4}\right)_{2} \cdot \mathrm{H}_{2} \mathrm{O}\right]$ and monetite $\left(\mathrm{CaHPO}_{4}\right)$, and emphasizes the importance of using a combined experimental/computational approach, notably for nuclei like oxygen-17. The second concerns high-field fast MAS ${ }^{1} \mathrm{H}$ and ${ }^{31} \mathrm{P}$ NMR experiments on biological specimens (mice teeth) to demonstrate how high-resolution spectra can now be obtained in a reasonable time on very small volumes of sample.

\section{EXPERIMENTAL DETAILS}

\section{A. Sample preparation and origin}

\section{Preparation of ${ }^{17} \mathrm{O}$-labeled samples}

${ }^{17} \mathrm{O}$-labeled MCPM, $\mathrm{Ca}\left(\mathrm{H}_{2} \mathrm{PO}_{4}\right)_{2} \cdot \mathrm{H}_{2} \mathrm{O}$ was synthesized by reacting $0.474 \mathrm{~g}(2 \mathrm{eq})$ of phosphoric acid $\left(\mathrm{H}_{3} \mathrm{PO}_{4}, 85 \%\right)$ with $0.206 \mathrm{~g}$ of $\mathrm{CaCO}_{3}(1 \mathrm{eq})$ at room temperature and under stirring, until precipitation of the powder was observed. $1.147 \mathrm{~g}$ of $40 \%$ labeled water, $\mathrm{H}_{2}{ }^{17} \mathrm{O}$, was used as the solvent. The precipitate corresponds to pure MCPM as shown by powder XRD and is referred to as MCPM hereafter. This protocol led to the ${ }^{17} \mathrm{O}$ labeling of the water molecule only (see later), the sample prepared being $\mathrm{Ca}\left(\mathrm{H}_{2} \mathrm{PO}_{4}\right)_{2} \cdot \mathrm{H}_{2}{ }^{17} \mathrm{O}$.

In a second synthetic approach, labeled phosphoric acid $\left(\mathrm{H}_{3} \mathrm{P}^{17} \mathrm{O}_{4}\right)$ was first obtained by reacting $1.064 \mathrm{~g}$ of $\mathrm{PCl}_{5}$ (98\% purity) with $0.512 \mathrm{~g}$ of $40 \%$-labeled $\mathrm{H}_{2}{ }^{17} \mathrm{O}$ to form $\mathrm{H}_{3} \mathrm{P}^{17} \mathrm{O}_{4}$. The reaction medium was stirred under argon in ice for $30 \mathrm{~min}$ and then heated at $90^{\circ} \mathrm{C}$ for $2 \mathrm{~h} .0 .299 \mathrm{~g}$ of $\mathrm{CaCO}_{3}$ were then added, together with $0.5 \mathrm{~g}$ of $20 \%$-labeled $\mathrm{H}_{2}{ }^{17} \mathrm{O}$ and $0.5 \mathrm{~g}$ of $40 \%$-labeled $\mathrm{H}_{2}{ }^{17} \mathrm{O}$, and the reaction medium was stirred at room temperature. This protocol led to a mixture of ${ }^{17} \mathrm{O}$-labeled phases, MCPM $\left[\mathrm{Ca}\left(\mathrm{H}_{2} \mathrm{P}^{17} \mathrm{O}_{4}\right)_{2} \cdot \mathrm{H}_{2}{ }^{17} \mathrm{O}\right]$ and monetite $\left(\mathrm{CaHP}^{17} \mathrm{O}_{4}\right)$. Powder XRD shows that the material is mainly composed of $\sim 60 \% \mathrm{MCPM}$ and $\sim 40 \%$ monetite (see Figure S1, in supplementary materials). This sample thus is referred to as MCPM-monetite in the rest of this article. It should be noted that considering the synthetic procedure used (i.e., hydrolysis of a chlorinated precursor by ${ }^{17} \mathrm{O}$-enriched water), the level of labeling of each phosphate oxygen atom in the MCPM and monetite components of the mixture is expected to be the same.

\section{Biological specimens}

Four-week-old mice (breed C57BL/6) were anaesthetized then decapitated after cervical dislocation. First lower molars were extracted under a dissecting microscope and frozen at $-20^{\circ} \mathrm{C}$ before NMR examination. All experiments were performed in accordance with the principles and guidelines established by the Institut National de la Santé et de la Recherche Medical (INSERM) employing the principles and procedures dictated by the highest standards of humane animal care.

\section{B. Solid state NMR experiments}

\section{1. ${ }^{17} \mathrm{O},{ }^{1} \mathrm{H}$, and ${ }^{31} \mathrm{P}$ solid state NMR experiments} on MCPM and MCPM-monetite

\section{a. ${ }^{17} \mathrm{O}$ solid state NMR}

${ }^{17} \mathrm{O}$ MAS NMR experiments on MCPM-monetite were performed on Avance $\mathrm{II}^{+}$and Avance III Bruker NMR spectrometers (Bruker, Karlsruhe, Germany) operating at 14.1 and 17.6 T, respectively. MAS Bruker probes of 3.2 and $4 \mathrm{~mm}$ were used with sample spinning frequencies of 24 and $14 \mathrm{kHz}$, respectively. Central transition (CT) MAS spectra were recorded using single-pulse and rotor-synchronized Hahn echo sequences $\left(90^{\circ}-\tau-180^{\circ}\right)$, with CT selective $90^{\circ}(6.2 \mu \mathrm{s})$ and $180^{\circ}(12.4 \mu \mathrm{s})$ pulses (nutation frequency of $13 \mathrm{kHz}$ ). ${ }^{17} \mathrm{O} 3 \mathrm{Q}-\mathrm{MAS}$ experiments were performed at 17.6 T using the z-filter three pulse sequence. ${ }^{46}$ A Bruker 3.2-mm MAS probe was used with a spinning frequency of $24 \mathrm{kHz}$. Spinal $64{ }^{1} \mathrm{H}$ decoupling ${ }^{47}$ was applied during the acquisition of the ${ }^{17} \mathrm{O}$ NMR signals. $90 t_{1}$ increments of $41.67 \mu \mathrm{s}$ (i.e., one rotor period) with 360 transients each were recorded. Quadrature detection in the indirect dimension was achieved using the States method.

${ }^{17} \mathrm{O}$ double rotation (DOR) experiments on MCPMmonetite were performed on an Avance $\mathrm{II}^{+}$Bruker NMR spectrometer operating at $14.1 \mathrm{~T}$ with a DOR probe designed by A. Samoson. ${ }^{42}$ In this case, no ${ }^{1} \mathrm{H}$ decoupling was applied during the acquisition of the ${ }^{17} \mathrm{O}$ signals. Before the experiments, the samples were diluted in unlabeled $\mathrm{MgO}$ to facilitate the combined rotation of the DOR rotors.

The ${ }^{17} \mathrm{O}$ solid state NMR spectrum of MCPM was recorded on a Bruker Avance II $^{+} 600$ spectrometer operating at $14.1 \mathrm{~T}$, using a Varian $3.2 \mathrm{~mm}$ MAS T3 probe and a spinning frequency of $20 \mathrm{kHz}$. The CT MAS spectrum was acquired with a rotor-synchronized Hahn echo experiment, with solid $90^{\circ}$ and $180^{\circ}$ pulse lengths of 1.0 and $2.0 \mu \mathrm{s}$, respectively (nutation frequency of $83 \mathrm{kHz}$ ). A total of 17,200 transients were averaged using a recycle delay of $5.0 \mathrm{~s}$.

All ${ }^{17} \mathrm{O}$ NMR spectra were externally referenced to $\mathrm{H}_{2} \mathrm{O}$ (tap water) at $0 \mathrm{ppm}$. For further details on individual experiments, please see the relevant figure captions.

\section{b. ${ }^{1} \mathrm{H}$ and ${ }^{31} \mathrm{P}$ solid state NMR}

${ }^{31} \mathrm{P}$ MAS experiments were performed at $7.0 \mathrm{~T}$ and $17.6 \mathrm{~T}$ on Avance III Bruker NMR spectrometers using $4 \mathrm{~mm}$ MAS Bruker probes. $\left\{{ }^{31} \mathrm{P}^{17} \mathrm{O}\right\}$ J-MAS-HMQC (Heteronuclear Multiple Quantum Coherence) experiments were performed at $17.6 \mathrm{~T}$ using a $3.2 \mathrm{~mm}$ MAS Bruker probe. ${ }^{31} \mathrm{P}$ chemical shifts were referenced to $\mathrm{H}_{3} \mathrm{PO}_{4}, 85 \%$ at $0 \mathrm{ppm}$.

${ }^{1} \mathrm{H}$ experiments were performed at $300,400,700$, and $750 \mathrm{MHz}$ using 4, 2.5, and $1.3 \mathrm{~mm}$ Bruker MAS probes. The ${ }^{1} \mathrm{H}-{ }^{1} \mathrm{H}$ 2D Frequency Switched Lee Goldburg (FSLG) experiments ${ }^{48,49}$ were performed at $17.6 \mathrm{~T}$ (4 mm probe). ${ }^{1} \mathrm{H}$ chemical shifts were referenced to tetramethylsilane $\left({ }^{1} \mathrm{H}\right)$ at $0 \mathrm{ppm}$. 
For further details on individual experiments, please see the relevant figure captions.

\section{2. ${ }^{1} \mathrm{H}$ and ${ }^{31} \mathrm{P}$ solid state NMR experiments on a mouse tooth}

The ${ }^{1} \mathrm{H}$ and ${ }^{31} \mathrm{P}$ solid state NMR experiments on the ground mouse tooth were recorded on a Bruker Avance III 750 (17.6 T) spectrometer using a Bruker 1.3 mm MAS HX probe spinning at $50 \mathrm{kHz}$. The temperature was regulated to $273 \mathrm{~K}$ to avoid any overheating of the sample during the experiments. ${ }^{1} \mathrm{H}$ single-pulse and rotor-synchronized Hahn echo NMR experiments were recorded using a $1.3 \mu \mathrm{s} 90^{\circ}$ pulse (and $2.6 \mu \mathrm{s} 180^{\circ}$ pulse) and a recycle delay of $5 \mathrm{~s} ; 32$ transients were acquired for each spectrum. For the ${ }^{1} \mathrm{H}$ Hahn echo experiment, an interpulse delay $\tau=0.1 \mathrm{~ms}$ was used (corresponding to 50 rotor periods). The ${ }^{31} \mathrm{P}$ singlepulse NMR experiment was performed using a $0.7-\mu$ s pulse $\left(30^{\circ}\right.$ flip angle) with a recycle delay of $30 \mathrm{~s}$. A total of 212 transients were acquired and spinal-64 ${ }^{1} \mathrm{H}$ decoupling was applied during the acquisition. ${ }^{1} \mathrm{H} \rightarrow{ }^{31} \mathrm{P}$ 1D CPMAS experiments were carried out using square-shaped contact pulses, for contact times of $0.3,1$, and $6 \mathrm{~ms}$. A total of 640 transients were acquired for each spectrum, and spinal- $64{ }^{1} \mathrm{H}$ decoupling was applied during the acquisition. ${ }^{1} \mathrm{H} \rightarrow{ }^{31} \mathrm{P}$ 2D HETCOR CPMAS spectra were recorded with contact times of 1,6 (with 264 transients for each $t_{1}$ increment), and $0.3 \mathrm{~ms}$ (with 512 transients for each $\mathrm{t}_{1}$ increment). The recycle delay was set to $1 \mathrm{~s}$. Quadrature detection in the indirect dimension was achieved using the States method. ${ }^{1} \mathrm{H}$ and ${ }^{31} \mathrm{P}$ NMR spectra were referenced to tetramethylsilane (at $0 \mathrm{ppm}$ ) and $\mathrm{NH}_{4} \mathrm{H}_{2} \mathrm{PO}_{4}$ (at $0.9 \mathrm{ppm}$ ), respectively.

\section{GIPAW calculations}

The calculations were performed within Kohn-Sham DFT using the PARAllel Total Energy Code code. ${ }^{50}$ The PBE-generalized gradient approximation ${ }^{51}$ was used and the valence electrons were described by norm conserving pseudopotentials $^{52}$ in the Kleinman-Bylander form. ${ }^{53}$ The core definition for $\mathrm{O}$ is $1 \mathrm{~s}^{2}$ and $1 \mathrm{~s}^{2} 2 \mathrm{~s}^{2} 2 \mathrm{p}^{6}$ for $\mathrm{P}$ and $\mathrm{Ca}$. The core radii are 1.2 a.u. for $\mathrm{H}, 1.5$ a.u. for $\mathrm{O}$, and 2.0 a.u. for $\mathrm{P}$ and $\mathrm{Ca}$. The wave functions are expanded on a plane wave basis set with a kinetic energy cutoff of 80 Ry (it was verified that with this cutoff the calculations have properly converged). The crystalline structure is described as an infinite periodic system using periodic boundary conditions. The NMR calculations were performed for the experimental geometries determined by neutron diffraction for $\mathrm{MCPM}^{54}$ and monetite (as calculations carried out on relaxed structures did not appear to lead to better results); the atomic forces in these structures were found to be $<0.15 \mathrm{eV} / \AA .{ }^{55}$ In the calculations, absolute shielding tensors are obtained. To fix the ${ }^{17} \mathrm{O}$ NMR scales, $\sigma^{\text {ref }}$ was chosen in such a way that the sum of all calculated $\sigma_{\text {iso }}$ for a series of $\mathrm{SiO}_{2}$ polymorphs coincides with the corresponding sum of experimental values. ${ }^{56}$

\section{RESULTS AND DISCUSSION}

\section{A. High-resolution solid state NMR studies of MCPM and MCPM-monetite}

\section{Synthetic approaches for ${ }^{17} \mathrm{O}$-labeled calcium phosphates}

In the framework of inorganic and hybrid calcium phosphate materials, several ${ }^{17} \mathrm{O}$ labeling schemes have been proposed in the literature. Cherry et al. performed the reaction of red phosphorus at $300{ }^{\circ} \mathrm{C}$ under reduced pressure with ${ }^{17} \mathrm{O}_{2}$ gas, ending with $\mathrm{P}_{2}{ }^{17} \mathrm{O}_{5}$ vapor. After condensation, $\mathrm{P}_{4}{ }^{17} \mathrm{O}_{10}$ was finally obtained. ${ }^{57}$ Using this synthetic process, labeling is optimal but strictly anhydrous experimental conditions are required. Flambard et al. used the reactivity of powdered solids with $\mathrm{H}_{2}{ }^{17} \mathrm{O}$ vapor by designing a purpose-built furnace. ${ }^{58}$ In this case, the key parameters are the temperature of the furnace (related to the reactivity of the enriched water vapor with the solid sample) and the experimental time monitoring the final labeling percentage. ${ }^{17} \mathrm{O}$-labeled water has also been used as a reactant in sol-gel chemistry reactions at room temperature to prepare ${ }^{17} \mathrm{O}$-labeled oxides. ${ }^{59}$ However, in the case of phosphates or phosphonates, the phosphoric or phosphonic acid precursors do not react with water under mild conditions (which shows that there is no nucleophilic attack of water at the phosphorus atom). It is thus necessary to first prepare in a separate step ${ }^{17} \mathrm{O}$-labeled phosphoric or phosphonic acid precursors, by reaction of chlorinated phosphorus compounds with enriched water. ${ }^{60}$ This approach is robust and is characterized by minimal losses in ${ }^{17} \mathrm{O}$. In particular, the reaction of $\mathrm{PCl}_{5}$ with $\mathrm{H}_{2}{ }^{17} \mathrm{O}$, leads to labeled phosphoric acid, $\mathrm{H}_{3} \mathrm{P}^{17} \mathrm{O}_{4}$, which can then be used as a precursor for standard sol-gel chemistry. In this work, pure MCPM, $\mathrm{Ca}\left(\mathrm{H}_{2} \mathrm{PO}_{4}\right)_{2} \cdot \mathrm{H}_{2}{ }^{17} \mathrm{O}$, and a mixture of MCPM-monetite, $\mathrm{Ca}\left(\mathrm{H}_{2} \mathrm{P}^{17} \mathrm{O}_{4}\right)_{2} \cdot \mathrm{H}_{2}{ }^{17} \mathrm{O}-\mathrm{CaHP}{ }^{17} \mathrm{O}_{4}$, were prepared by sol-gel reactions starting with $\mathrm{H}_{2}{ }^{17} \mathrm{O}$ and $\mathrm{H}_{3} \mathrm{P}^{17} \mathrm{O}_{4} / \mathrm{H}_{2}{ }^{17} \mathrm{O}$, respectively (see the Experimental section for details).

\section{2. ${ }^{17} \mathrm{O}$ NMR spectroscopy and GIPAW calculations}

The ${ }^{17} \mathrm{O}$ MAS spectrum of MCPM recorded on a $600-\mathrm{MHz}$ NMR spectrometer is presented in Fig. 1(a). A single resonance characterized by a second-order broadened quadrupolar lineshape is observed $\left(\delta_{\text {iso }}=14.0 \pm 5.0\right.$ ppm, $\mathrm{C}_{\mathrm{Q}}=6.3 \pm 0.4 \mathrm{MHz}, \eta_{\mathrm{Q}}=0.85 \pm 0.15$, see Table II). The large $\mathrm{C}_{\mathrm{Q}}$ value is characteristic of the structural water molecules of MCPM, excluding therefore the contribution of mobile water molecules adsorbed onto the MCPM crystals. Comparing the ${ }^{17} \mathrm{O}$ quadrupolar parameters calculated by GIPAW ${ }^{21}$ with the experimental data, the 


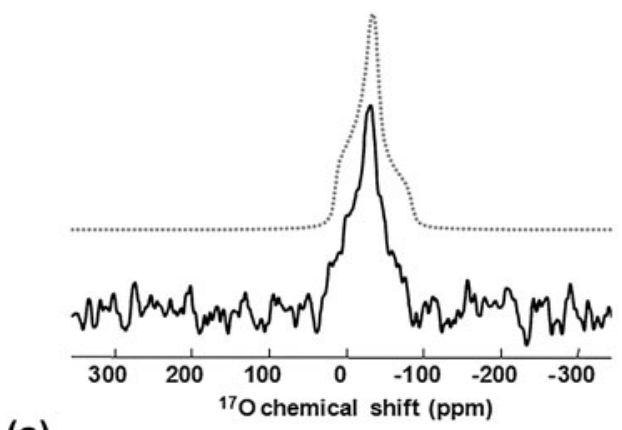

(a)

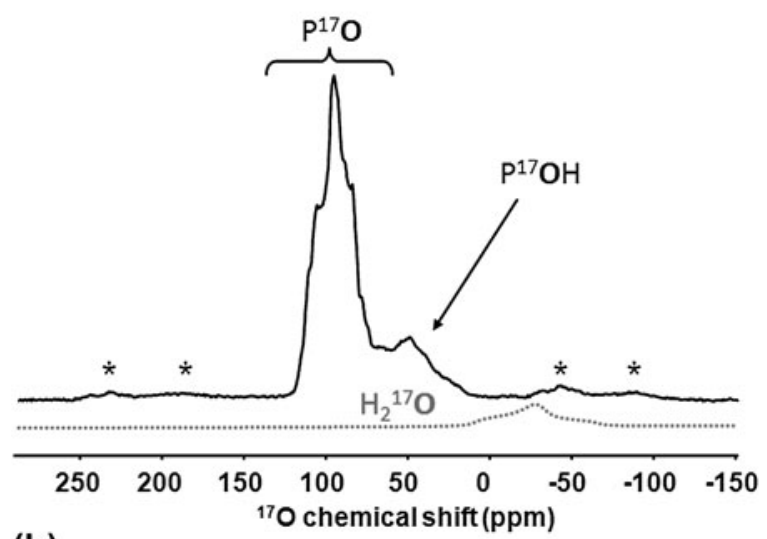

(b)

FIG. 1. (a) ${ }^{17} \mathrm{O}$ MAS NMR spectrum of MCPM at $14.1 \mathrm{~T}(3.2 \mathrm{~mm}$ rotor, recycle delay: $5 \mathrm{~s}$, number of scans: $17196, v_{\text {rot }}: 20 \mathrm{kHz},{ }^{1} \mathrm{H}$ decoupling). The dotted spectrum corresponds to a simulation ${ }^{61}$ with a second-order quadrupolar interaction. (b) ${ }^{17} \mathrm{O}$ Hahn echo MAS NMR spectrum of MCPM-monetite at $17.6 \mathrm{~T}(4 \mathrm{~mm}$, recycle delay: $15 \mathrm{~s}$, number of scans: $64, v_{\text {rot }}: 14 \mathrm{kHz},{ }^{1} \mathrm{H}$ decoupling). The dotted spectrum corresponds to the expected $\mathrm{H}_{2}{ }^{17} \mathrm{O}$ signal of MCPM with the quadrupolar parameters given in the text (and the intensity expected with respect to the composition of the sample). '*' spinning side bands; MAS, Magic Angle Spinning; NMR, Nuclear Magnetic Resonance; MCPM, monocalcium phosphate monohydrate.

TABLE II. Comparison of calculated and experimental ${ }^{17} \mathrm{O}$ NMR parameters.

\begin{tabular}{lcc}
\hline \hline & Experimental values & Calculated values \\
\hline $\mathrm{H}_{2} \mathrm{O}$ in MCPM & & \\
$\delta_{\text {iso. }}(\mathrm{ppm})$ & $14.0 \pm 5.0$ & -0.9 \\
$\mathrm{C}_{\mathrm{Q}}(\mathrm{MHz})$ & $6.3 \pm 0.4$ & 7.63 \\
$\eta_{\mathrm{Q}}$ & $0.85 \pm 0.15$ & 0.82 \\
$\mathrm{PO}$ in MCPM-monetite & & \\
$\delta_{\text {iso. }}(\mathrm{ppm})$ & $95-123$ & $91-125$ \\
$\mathrm{C}_{\mathrm{Q}}(\mathrm{MHz})$ & $\sim 4.5 \pm 0.5$ & $4.37-4.27$ \\
$\eta_{\mathrm{Q}}$ & $\sim 0.2 \pm 0.2$ & $0.07-0.57$ \\
\hline \hline
\end{tabular}

MCPM, monocalcium phosphate monohydrate.

resonances related to $\mathrm{P}^{17} \mathrm{O}$ and $\mathrm{P}^{17} \mathrm{OH}$ groups are obviously not observed (as confirmed below by the analysis of the MCPM-monetite sample). This is not surprising given that this synthetic approach of MCPM involves nonlabeled $\mathrm{H}_{3} \mathrm{PO}_{4}$, and no $\mathrm{P}-\mathrm{OH} / \mathrm{H}_{2} \mathrm{O}$ exchange is expected under the conditions used here. Only the selective enrich- ment of the $\mathrm{H}_{2} \mathrm{O}$ molecules thus occurs. The ${ }^{17} \mathrm{O}$ GIPAW parameters for these structural water molecules are ${ }^{21}$ : $\delta_{\text {iso }}=-0.9 \mathrm{ppm}, \mathrm{C}_{\mathrm{Q}}=7.63 \mathrm{MHz}, \eta_{\mathrm{Q}}=0.82$. One notices a moderate overestimation of the quadrupolar constant $\mathrm{C}_{\mathrm{Q}}$, as already stressed in several articles. ${ }^{62,63}$ The largest discrepancy between calculated and experimental values is for $\delta_{\text {iso, }}$, as the difference observed ( $\sim 15 \mathrm{ppm}$; see Table II) is larger than the estimated accuracy of ${ }^{17} \mathrm{O}$ isotropic chemical shifts calculated by GIPAW ( \pm 3 ppm). ${ }^{60,64}$ Nevertheless, it would be worth seeing whether it is possible to reduce such a discrepancy (i) by obtaining more accurate experimental NMR data, for instance by recording an additional experimental spectrum of MCPM at a higher magnetic field (as attempts to record the spectrum on a lower field magnet led to a very noisy/unexploitable spectrum, even after $48 \mathrm{~h}$ of acquisition), and simulating the spectra recorded at both magnetic fields, and (ii) by evaluating more precisely the accuracy of GIPAW calculations, when it comes to calculating the ${ }^{17} \mathrm{O}$ NMR parameters for water molecules. Indeed, to the best of our knowledge, these data correspond to the first ones ever reported for water molecules in calcium phosphates.

The ${ }^{17} \mathrm{O}$ echo MAS spectrum of MCPM-monetite is presented in Fig. 1(b). Two main contributions centered at $\delta \sim 100$ and $\sim 50 \mathrm{ppm}$ are observed. They can be assigned safely to $\mathrm{P}^{17} \mathrm{O}$ and $\mathrm{P}^{17} \mathrm{OH}$ resonances, respectively. ${ }^{21}$ The quadrupolar constants for $\mathrm{P}^{17} \mathrm{O}$ are smaller than for $\mathrm{P}^{17} \mathrm{OH}$ (see Table II). ${ }^{21,64}$ This is in agreement with GIPAW calculations: for example, in the case of MCPM, the averaged GIPAW calculated $\mathrm{C}_{\mathrm{Q}}$ for $\mathrm{P}^{17} \mathrm{O}$ and $\mathrm{P}^{17} \mathrm{OH}$ are 4.63 and 7.20 MHz, respectively, leading to a much stronger quadrupolar broadening for $\mathrm{P}^{17} \mathrm{OH}$ groups, and a dramatic loss in signal-to-noise ratio. At this stage, it has to be emphasized that the complexity of the ${ }^{17} \mathrm{O}$ spectrum presented in Fig. 1(b) is due to a large number of independent crystallographic oxygen sites: 9 for MCPM, including one unique water ${ }^{17} \mathrm{O}$ site (see JCPDS number 700090), and 16 for monetite. ${ }^{55}$ Assuming a 60/40 mixture of MCPM and monetite (see the Experimental section), the percentage of $\mathrm{P}^{17} \mathrm{O}, \mathrm{P}^{17} \mathrm{OH}$, and $\mathrm{H}_{2}{ }^{17} \mathrm{O}$ groups can be estimated to $\sim 56,37$, and $7 \%$, respectively. It follows that the $\mathrm{H}_{2}{ }^{17} \mathrm{O}$ resonance is not detected in Fig. 1(b), mainly because of its low content in this mixture.

\section{High-resolution ${ }^{17} \mathrm{O}$ and ${ }^{31} \mathrm{P}$ NMR experiments}

To increase the resolution of the ${ }^{17} \mathrm{O}$ NMR spectrum of MCPM-monetite, MQ-MAS ${ }^{46,65}$ and DOR ${ }^{42,66,67}$ experiments were performed at very high magnetic field. Both aim at obtaining high-resolution spectra of quadrupolar nuclei by removing the second-order quadrupolar interaction. ${ }^{42}$ In brief, the former experiment consists on recording a 2D spectrum under MAS in which highly resolved isotropic peaks are obtained in the indirect dimension, whereas the latter consists on spinning the sample at two different angles simultaneously to average out the quadrupolar 


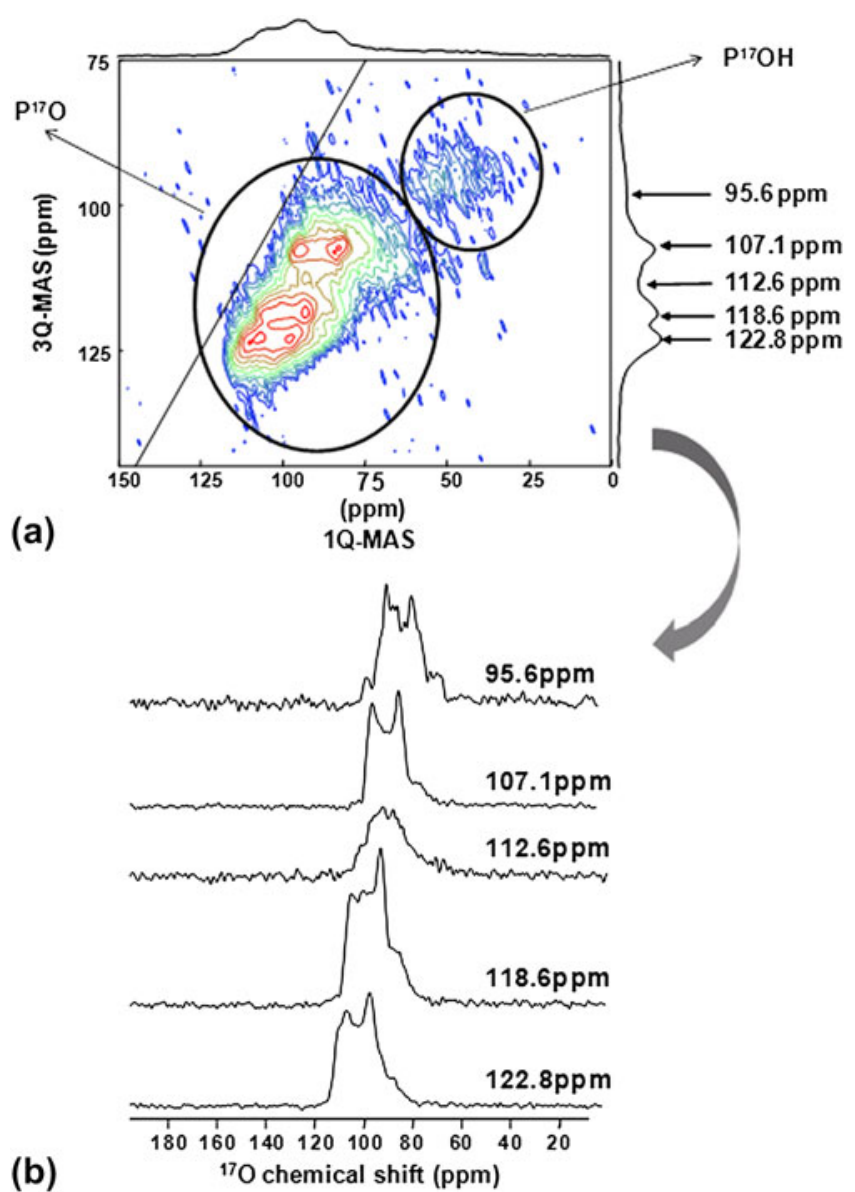

FIG. 2. (a) ${ }^{17} \mathrm{O} 3 \mathrm{Q}-\mathrm{MAS}$ NMR spectrum of MCPM-monetite at $17.6 \mathrm{~T}$ (3.2 mm, recycle delay: $2 \mathrm{~s}, v_{\text {rot }}: 24 \mathrm{kHz},{ }^{1} \mathrm{H}$ decoupling). The $\mathrm{P}^{17} \mathrm{O}$ and $\mathrm{P}^{17} \mathrm{OH}$ regions are indicated. (b) Isotropic contributions to the highly resolved dimension and the corresponding MAS lineshapes.

interaction, and a well resolved 1D spectrum with isotropic lines can thus be obtained. ${ }^{42}$ The ${ }^{17} \mathrm{O}$ 3Q-MAS spectrum of MCPM-monetite is presented in Fig. 2. Two regions are clearly distinguished. The $\mathrm{P}^{17} \mathrm{OH}$ region is characterized by a low signal/noise ratio, as it corresponds to the strongest $\mathrm{C}_{\mathrm{Q}}$ constants; this part of the spectrum will not be commented further. The $\mathrm{P}^{17} \mathrm{O}$ region exhibits several ${ }^{17} \mathrm{O}$ isotropic contributions in the 3Q-MAS dimension (some of the corresponding lineshapes in the 95.6 to $122.8 \mathrm{ppm}$ range are presented). At this stage, it is not possible to extract the individual NMR parameters for all ${ }^{17} \mathrm{O}$ sites involved in the MCPM-monetite mixture (due to the significant spectral overlap). Nevertheless, estimations of $\delta_{\text {iso }}$, $\mathrm{C}_{\mathrm{Q}}$, and $\eta_{\mathrm{Q}}$ can be given, as shown in Table II. Such estimates are in general in good agreement with the corresponding isotropic shift ranges obtained by GIPAW (all the GIPAW calculated values for MCPM-monetite are given in Table S1 in supplementary information).

The 1D ${ }^{17} \mathrm{O}$ DOR NMR experiment leads also to the complete averaging of the second-order quadrupolar effects. Recently, DOR has been implemented to study organic and inorganic phases in combination with more involved pulse sequences, such as spin diffusion and MQ-DOR ${ }^{67}$ The DOR spectrum of MCPM-monetite at 14.1 T, together with the corresponding MAS spectrum, are presented in Figs. 3(a) and 3(b), respectively. A spectacular increase in resolution is observed. The chemical shift range of the peaks shows that they correspond to $\mathrm{P}^{17} \mathrm{O}$ resonances. The $\mathrm{P}^{17} \mathrm{OH}$ resonances are not detected, because no ${ }^{1} \mathrm{H}$ decoupling scheme was applied during the acquisition of the ${ }^{17} \mathrm{O}$ signals. Most of the $\mathrm{P}^{17} \mathrm{O}$ resonances obtained are sharp $(\sim 60 \mathrm{~Hz})$ and correspond obviously to doublets. Two isotropic components at $\sim 75$ and $\sim 100 \mathrm{ppm}$ are nevertheless broader, without any evidence of $\mathbf{J}$ splitting; motional averaging and/or particular relaxation effects could explain this observation. The doublets observed for the sharp signals are expected from isotropic ${ }^{1} \mathrm{~J}_{\mathrm{O}-\mathrm{P}}$ coupling constants, as $\mathrm{I}=1 / 2$ and $100 \%$ natural abundance for ${ }^{31} \mathrm{P}$ (see Table I). The average value of $\left|{ }^{1} \mathrm{~J}_{\mathrm{O}-\mathrm{P}}\right|$ coupling constants is estimated as $\sim 160 \mathrm{~Hz}$. Such values are comparable to those obtained for other compounds containing $\mathrm{P}-\mathrm{O}$ bonds. ${ }^{68-70}$ They will be compared to GIPAW calculations in the near future, following similar approaches as those previously published in the literature. ${ }^{71}$ It has to be noticed that the ${ }^{17} \mathrm{O}$ DOR experiments led easily to the observation of the J-multiplet patterns, whereas such data would have been very hard to obtain by standard ${ }^{17} \mathrm{O}$ MQ-MAS experiments. By measuring the center of gravity of all doublets and by taking into account the DOR isotropic shift expression, ${ }^{42}$ it is possible to recalculate the true ${ }^{17} \mathrm{O}$ isotropic chemical shifts of the various lines, using the averaged values $\mathrm{C}_{\mathrm{Q}} \sim 4.6 \mathrm{MHz}$ and $\eta_{\mathrm{Q}} \sim 0$, based on GIPAW results. The experimental centers of gravity correspond to two groups of four lines centered at $\delta_{\text {iso }}=95.2,101.1,102.1(\times 2) \mathrm{ppm}$ and $111.8,112.7,116.6,121.6 \mathrm{ppm}$. Taking into account Table S1, it is reasonable to assign the four more shielded resonances to MCPM. As a consequence, the four remaining lines are assigned to monetite. Strictly speaking, 12 isotropic lines ranging from 106.67 to $125.04 \mathrm{ppm}$ would have been expected for monetite given the number of crystallographically inequivalent $\mathrm{P}-\mathrm{O}$ sites, but such an ultimate resolution is not obtained even by DOR at $14.1 \mathrm{~T}$. Nevertheless, from these values, it was then possible to simulate the corresponding MAS spectrum in the PO region at $14.1 \mathrm{~T}$ (Fig. 4). The agreement with the experimental MAS spectrum is obviously good, and the accuracy of the simulation is further demonstrated by comparing the experimental MAS spectrum recorded at a higher magnetic field (17.6 T, see Figure S2 in supplementary materials), with the one simulated using the same set of NMR parameters.

Because the most accurate description of chemical bonds in NMR is given by the indirect spin-spin J-coupling which occurs through interatomic bonds, it is worth trying to evidence and measure $\mathrm{J}$-coupling values by NMR. It is 


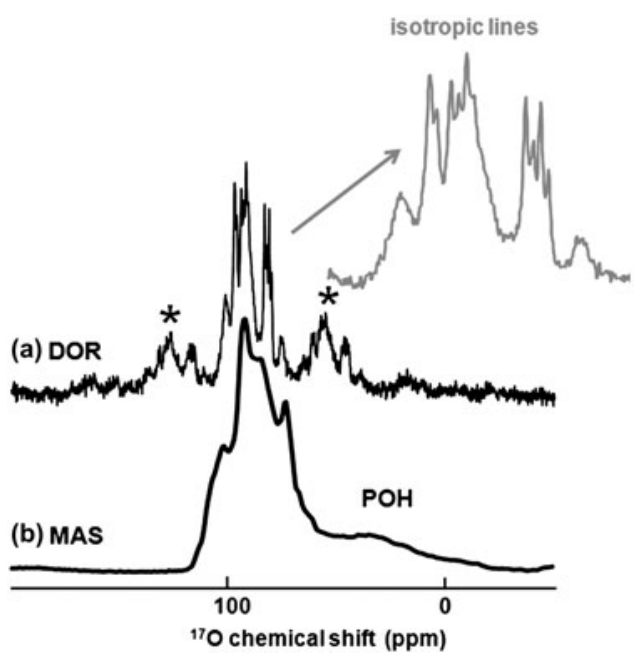

FIG. 3. (a) ${ }^{17} \mathrm{O}$ DOR NMR spectrum of MCPM-monetite at $14.1 \mathrm{~T}$ (recycle delay: $1 \mathrm{~s}$, number of scans: 5000 , inner $v_{\text {rot }}: 6.50 \mathrm{kHz}$, outer $v_{\text {rot }}: 1.44 \mathrm{kHz}$, no ${ }^{1} \mathrm{H}$ decoupling). Only the $\mathrm{P}^{17} \mathrm{O}$ groups are detected. '*' spinning side bands. In red: expansion of the DOR spectrum showing the $\mathrm{J}$ doublets $\left({ }^{1} \mathrm{~J}_{\mathrm{O}-\mathrm{P}}\right.$ couplings). The $\mathrm{P}^{17} \mathrm{OH}$ resonances are not detected (no ${ }^{1} \mathrm{H}$ decoupling, see text). (b) The corresponding ${ }^{17} \mathrm{O}$ echo MAS NMR spectrum at $14.1 \mathrm{~T}(4 \mathrm{~mm}$, recycle delay: $20 \mathrm{~s}$, number of scans: $3200, v_{\text {rot }}: 12.5 \mathrm{kHz},{ }^{1} \mathrm{H}$ decoupling). In this case the $\mathrm{P}^{17} \mathrm{OH}$ signals are observed. DOR, double rotation.

usually accepted that the J-coupling interaction is much less intense than the Chemical Shift Anisotropy (CSA), dipolar and quadrupolar interactions, ${ }^{42}$ making its measurement challenging. Therefore, very few $\mathbf{J}$ data for calcium phosphates have been published so far in the literature. It follows that $\mathrm{J}_{\mathrm{P}-\mathrm{O}}$ coupling constants appear as a new NMR observable which should be sensitive to subtle variations in the $\mathrm{P}-\mathrm{O}$ bonds. To measure ${ }^{1} \mathrm{~J}_{\mathrm{O}-\mathrm{P}}$ coupling constants, an alternate approach to the DOR study presented above (which relies on being equipped of a DOR probe) consists on performing high-resolution ${ }^{31} \mathrm{P}$ NMR spectroscopy experiments. The single-pulse ${ }^{31} \mathrm{P}$ MAS spectra of ${ }^{17} \mathrm{O}-$ labeled MCPMmonetite at various fields are presented in Figs. 5(a) and 5(b) (at 17.6 and 7.0 T, respectively). The spectrum obtained at $7.0 \mathrm{~T}$ is extremely broad and cannot be interpreted by a simple addition of the ${ }^{31} \mathrm{P}$ spectra of pure nonlabeled monetite [Fig. 5(c)] and MCPM [Fig. 5(d)]. A dramatic increase in resolution is observed at higher field [17.6 T, Fig. 5(a)]. The gain in resolution is related to ${ }^{31} \mathrm{P}-{ }^{17} \mathrm{O}$ secondorder heteronuclear dipolar coupling/quadrupolar effects, ${ }^{72}$ which decreases at higher magnetic field. Rather sharp lines are observed at $\delta_{\text {iso. }}=1.4,0.3$, and $-4.4 \mathrm{ppm}$. They are comparable to the resonances of pure monetite and MCPM and are therefore assigned to $\mathrm{P}^{16} \mathrm{O}_{4}$ groups. The asymmetric multiplet patterns observed around these main signals correspond to $\mathrm{P}^{16} \mathrm{O}_{3}{ }^{17} \mathrm{O}, \mathrm{P}^{16} \mathrm{O}_{2}{ }^{17} \mathrm{O}_{2}, \mathrm{P}^{16} \mathrm{O}^{17} \mathrm{O}_{3}$, and $\mathrm{P}^{17} \mathrm{O}_{4}$ groups with an increasing number of ${ }^{1} \mathrm{~J}_{\mathrm{P}-\mathrm{O}}$ couplings (it is noteworthy that the probability of having $\mathrm{P}^{17} \mathrm{O}_{4}$ groups is $<3 \%$, and can thus be neglected). In the case of partly enriched ${ }^{17} \mathrm{O}$ samples $(<40 \%)$, the analysis of these multi-

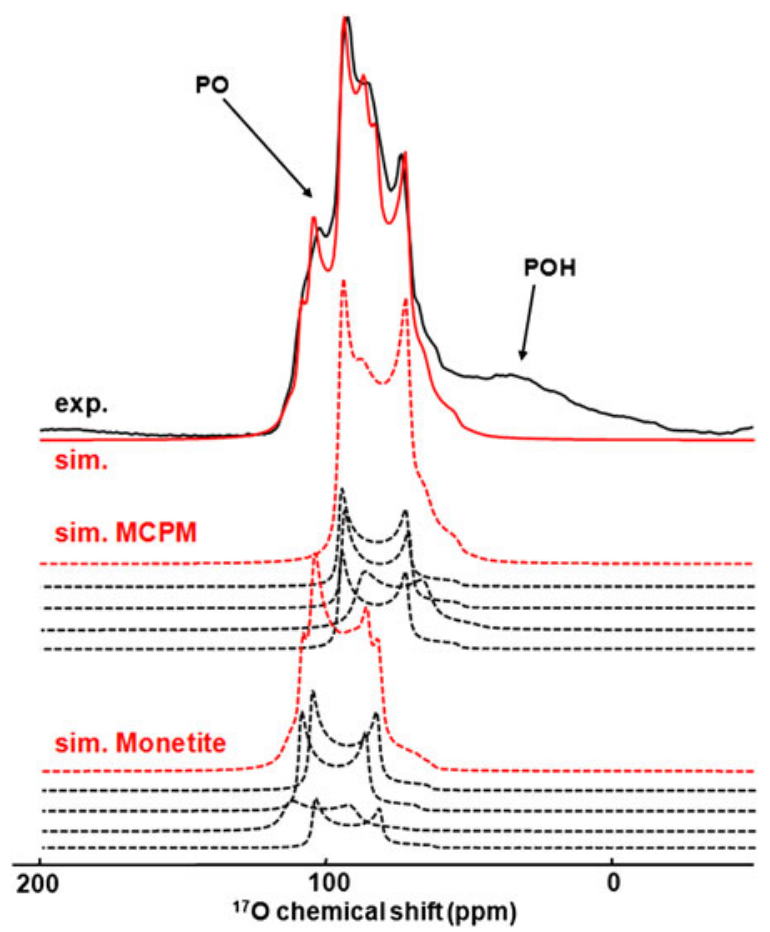

FIG. $4 .{ }^{17} \mathrm{O}$ MAS NMR spectrum of MCPM-monetite at $14.1 \mathrm{~T}$ in black, top spectrum. The simulation in the PO region (in red, top) corresponds to the sum of the contributions of MCPM and monetite (the isotropic chemical shifts were extracted from the DOR data, the quadrupolar parameters were estimated from GIPAW calculationssee text for further details).

plet patterns is not straightforward: assuming a unique ${ }^{1} \mathrm{~J}_{\mathrm{P}-\mathrm{O}}$ constant, $\mathrm{P}^{16} \mathrm{O}_{3}{ }^{17} \mathrm{O}, \mathrm{P}^{16} \mathrm{O}_{2}{ }^{17} \mathrm{O}_{2}$, and $\mathrm{P}^{16} \mathrm{O}^{17} \mathrm{O}_{3}$ groups should lead to 6,11 , and 16 lines shifted by second-order effects, respectively. Thus, it appears necessary to simplify the spectra. To suppress all components related to $\mathrm{P}^{16} \mathrm{O}_{4}$ groups, and to selectively observe only the central components of each J-multiplet (related to coupling with ${ }^{17} \mathrm{O}$ nuclei in the $1 / 2$ and $-1 / 2$ states), J-MAS-HMQC experiments can be implemented, ${ }^{73,74}$ using purge pulses and selective excitation of the ${ }^{17} \mathrm{O} C$ Ts. ${ }^{75}$ The $\left\{{ }^{31} \mathrm{P}-{ }^{17} \mathrm{O}\right\}$ J-MAS-HMQC spectrum of MCPM-monetite is presented in Fig. 6. Obviously, the sharp components $\left[\mathrm{P}^{16} \mathrm{O}_{4}\right.$, see Fig. 5(a)] have been efficiently suppressed. Moreover, doublets are observed and a ${ }^{1} \mathrm{~J}_{\mathrm{P}-\mathrm{O}}$ coupling constant $\sim 110 \mathrm{~Hz}$ can be estimated. This ${ }^{1} \mathrm{~J}_{\mathrm{P}-\mathrm{O}}$ coupling constant is fairly consistent with the DOR results, but it is slightly smaller. The discrepancy may be related to the fact that the $\left\{{ }^{31} \mathrm{P}_{-}{ }^{17} \mathrm{O}\right\}$ $\mathrm{J}$-MAS-HMQC experiment is slightly less accurate because the splitting observed is caused by all the different ${ }^{17} \mathrm{O}$ atoms bound to the phosphorous. In contrast, in the DOR experiment, the splitting is a more accurate measurement of ${ }^{1} \mathrm{~J}_{\mathrm{P}-\mathrm{O}}$ because each oxygen is connected to only one phosphorous.

The range of high-resolution ${ }^{17} \mathrm{O}$ and ${ }^{31} \mathrm{P}$ NMR experiments presented above demonstrates that it is now possible to characterize in detail calcium phosphate phases. Good agreement between experimental and calculated ${ }^{17} \mathrm{O}$ NMR 


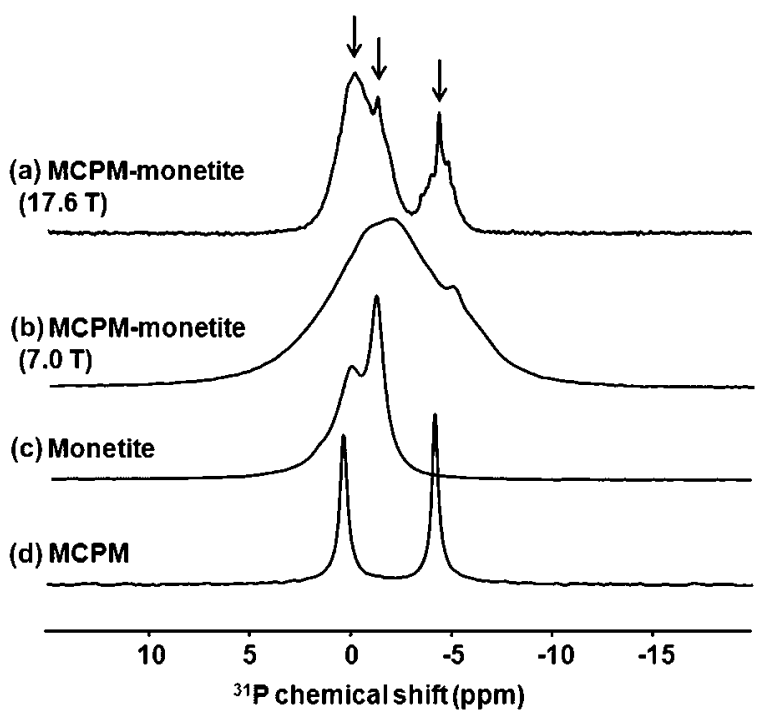

FIG. 5. ${ }^{31} \mathrm{P}$ MAS NMR spectra (a) ${ }^{17} \mathrm{O}$-labeled MCPM-monetite at $17.6 \mathrm{~T}\left(3.2 \mathrm{~mm}\right.$, recycle delay: $90 \mathrm{~s}$, number of scans: $16, v_{\text {rot }}: 24 \mathrm{kHz}$, ${ }^{1} \mathrm{H}$ decoupling $)$. b) ${ }^{17} \mathrm{O}$-labeled MCPM-monetite at $7.0 \mathrm{~T}(4 \mathrm{~mm}$, recycle delay: $30 \mathrm{~s}$, number of scans: $16, v_{\text {rot }}: 14 \mathrm{kHz},{ }^{1} \mathrm{H}$ decoupling). (c) Unlabeled monetite at $7.0 \mathrm{~T}(4 \mathrm{~mm}$, recycle delay: $30 \mathrm{~s}$, number of scans: $16, v_{\text {rot }}: 14 \mathrm{kHz},{ }^{1} \mathrm{H}$ decoupling). (d) Unlabeled MCPM at $7.0 \mathrm{~T}$ (4 mm, recycle delay: $30 \mathrm{~s}$, number of scans: $4, v_{\text {rot }}: 14 \mathrm{kHz},{ }^{1} \mathrm{H}$ decoupling). Vertical arrows: $\mathrm{P}^{16} \mathrm{O}_{4}$ resonances.

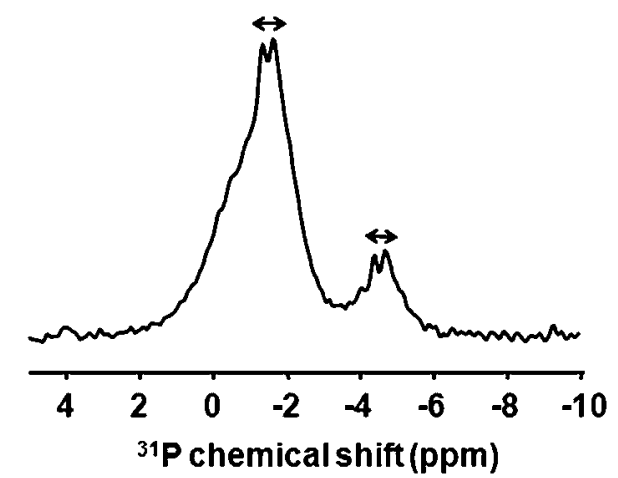

FIG. 6. $\left\{{ }^{31} \mathrm{P}_{-}{ }^{17} \mathrm{O}\right\}$ J-MAS-HMQC NMR spectrum of MCPM-monetite at $17.6 \mathrm{~T}\left(3.2 \mathrm{~mm}\right.$, recycle delay: $120 \mathrm{~s}$, number of scans: $64, v_{\text {rot: }}$ : $24 \mathrm{kHz}, \tau=3.6 \mathrm{~ms},{ }^{1} \mathrm{H}$ decoupling).

data for these two phases can be obtained, confirming the accuracy of ${ }^{17} \mathrm{O}$ NMR calculations. Determining ${ }^{31} \mathrm{P}-{ }^{17} \mathrm{O}$ J-couplings experimentally on calcium phosphates of known structure (like MCPM-monetite) is also particularly useful for helping in the development of DFT calculations of NMR parameters. Indeed, methods to calculate $\mathbf{J}$-coupling values have been proposed, and it is crucial to validate the accuracy of the computational methods used by comparing experimental and calculated values.

\section{High-resolution ${ }^{1} \mathrm{H}$ NMR spectroscopy}

The aim of this part is to demonstrate methods which can be used to obtain ${ }^{1} \mathrm{H}$ high-resolution NMR spectra.

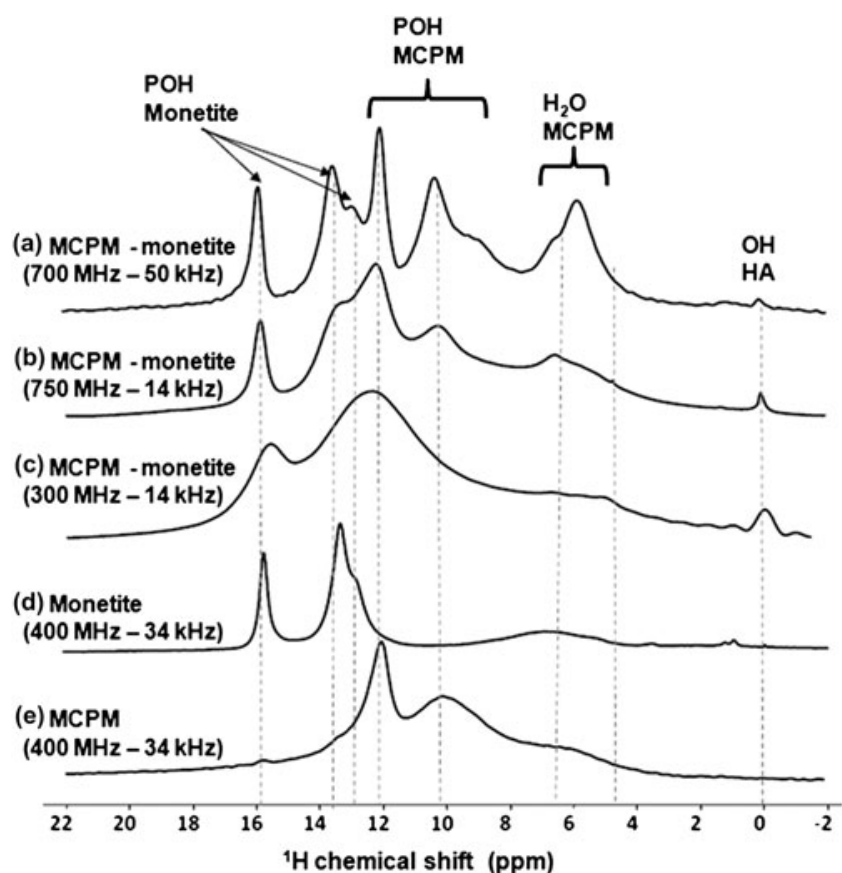

FIG. 7. ${ }^{1} \mathrm{H}$ NMR spectra of MCPM-monetite at various fields and the nonlabeled corresponding pure phases, and various spinning speeds $v_{\text {rot }}$ [4 mm (14 kHz), $2.5 \mathrm{~mm}(34 \mathrm{kHz}), 1.3 \mathrm{~mm}(50 \mathrm{kHz})$, recycle delay: from 5 to $60 \mathrm{~s}$, number of scans: 8]. (d) The spectrum of monetite shows the presence of water signals at $\sim 4$ to $7 \mathrm{ppm}$, suggesting that this phase was not well dried before the NMR measurement.

One possibility is to perform very fast MAS experiments (up to $67 \mathrm{kHz}$ ) at high magnetic field. The very fast MAS technique has led recently to spectacular results, especially for strongly coupled spins such as protons (the strong coupling corresponds here to the homonuclear dipolar interaction) ${ }^{76}$ Spinning at very high spinning speeds requires using small (1.3 mm diameter or less) rotors, which means that the mass of samples in the rotor is very limited $(\sim 5 \mathrm{mg}$ or less). This raises the fundamental question of sensitivity of the NMR experiments. As shown in Fig. 7 for MCPMmonetite, the ${ }^{1} \mathrm{H}$ sensitivity remains high even for small sample volumes. Furthermore, the comparison of spectra recorded spinning at $50 \mathrm{kHz}$ on a $750 \mathrm{MHz}$ spectrometer with those obtained at lower spinning speeds and/or lower magnetic fields clearly shows that the great advantage of increasing both the magnetic field $\mathrm{B}_{0}$ and the MAS frequency. At $750 \mathrm{MHz}$ and $v_{\text {rot }}=50 \mathrm{kHz}$, the resolution is optimal, and the resonances of the different crystallographically inequivalent $\mathrm{HPO}_{4}{ }^{2-}$ and $\mathrm{H}_{2} \mathrm{O}$ species become evident, when comparing with the spectra of phase pure MCPM and monetite samples. The small peak which appears at $\sim 0 \mathrm{ppm}$ probably corresponds to the $\mathrm{OH}$ resonance of a HA impurity in the sample ${ }^{20}$; the amount of this phase is very limited given that it is not detected by XRD.

Alternatively, to obtain high-resolution ${ }^{1} \mathrm{H}$ NMR data, 2D ${ }^{1} \mathrm{H}-{ }^{1} \mathrm{H}$ MAS experiments can be implemented at high field, in combination with homonuclear decoupling (here, 


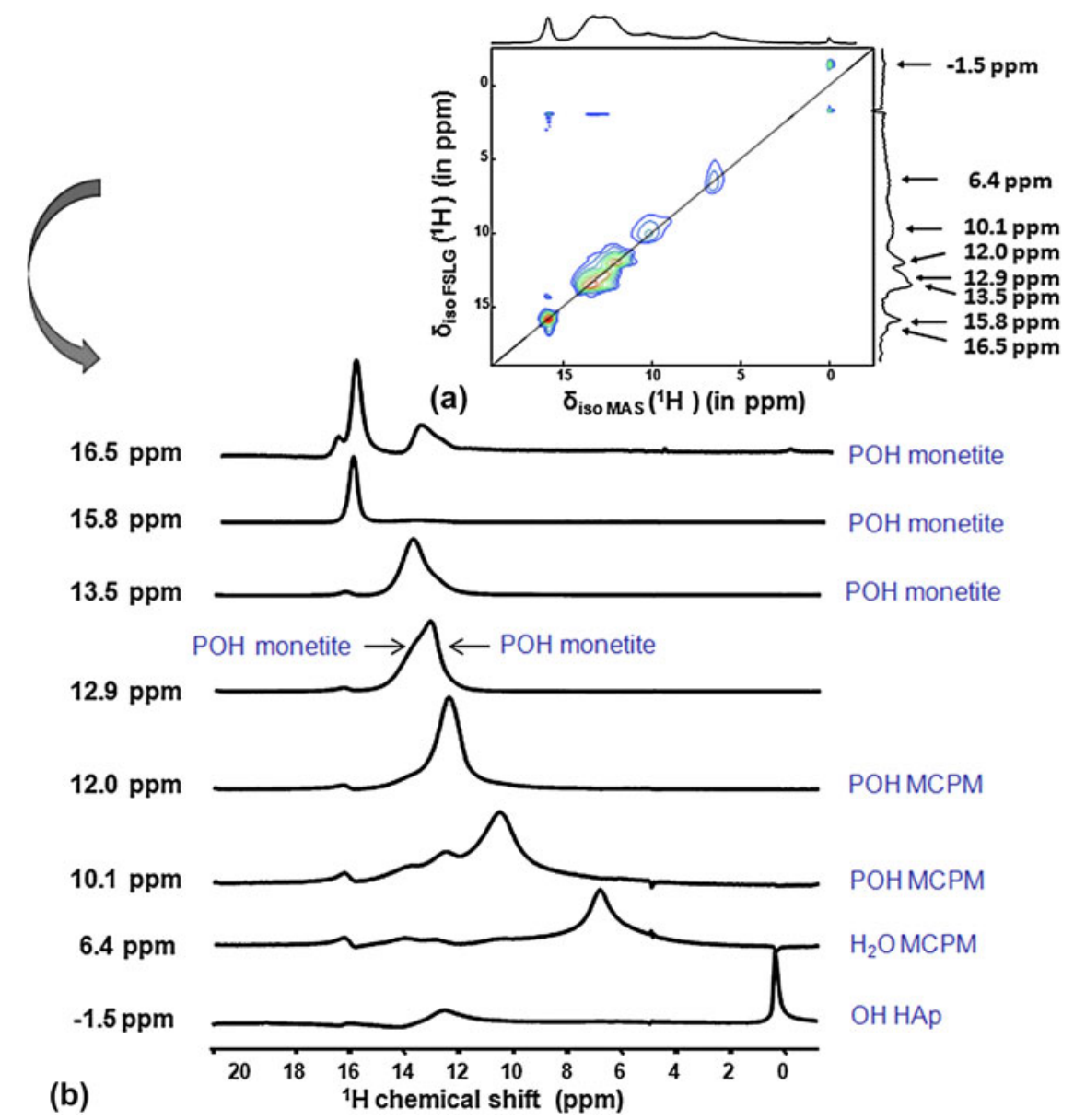

FIG. 8. (a) ${ }^{1} \mathrm{H}-{ }^{1} \mathrm{H}$ 2D Frequency Switched Lee Goldburg NMR spectrum of MCPM-monetite at $17.6 \mathrm{~T}$ (4 mm, recycle delay: $5 \mathrm{~s}$, number of scans: $16, v_{\text {rot }}: 14 \mathrm{kHz}$ ). (b) The corresponding isotropic contributions.

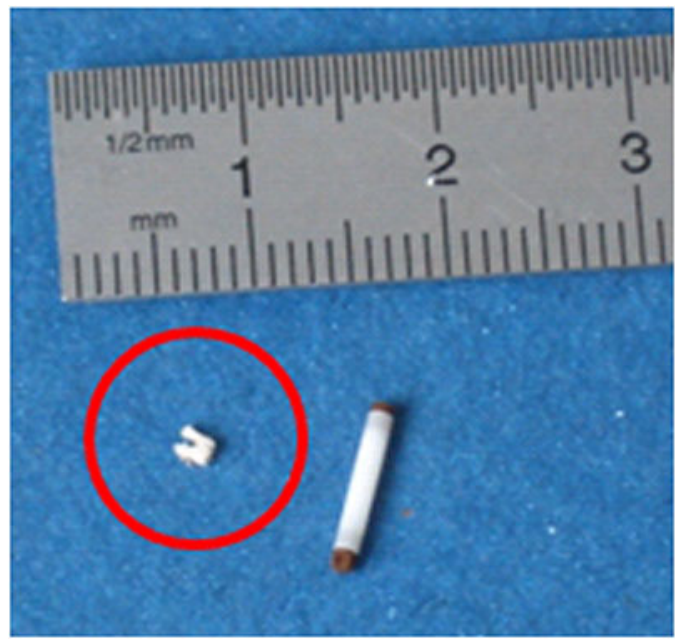

FIG. 9. Representation of mouth tooth (circled in red) and MAS rotor used.

FSLG). ${ }^{48,49,76}$ In Fig. 8(a), the 2D FSLG spectrum (after rescaling the indirect FSLG dimension) of MCPM-monetite is shown. Several isotropic slices are presented as well [Fig. 8(b)]: showing that all $\mathrm{P}-\mathrm{OH}$ and $\mathrm{H}_{2} \mathrm{O}$ resonances can be distinguished. It should be noted, however, that offresonance effects lead to incorrect rescaling of the HA resonance in the indirect FSLG dimension.

All in all, these experiments demonstrate that by combining high magnetic fields, fast MAS, and specific NMR pulse sequences, it is now possible to obtain highresolution ${ }^{17} \mathrm{O}$ and ${ }^{1} \mathrm{H}$ NMR spectra on complex mixtures of calcium phosphates (like the MCPM-monetite sample). The focus of the next section is to show how some of these techniques can be applied to the characterization of biological calcium phosphates.

\section{B. ${ }^{31} \mathrm{P}$ and ${ }^{1} \mathrm{H}$ solid state NMR experiments of mice teeth}

As shown in Fig. 9, the 1.3-mm-diameter rotors mentioned above are perfectly adapted to the study of very small biological samples like mice teeth. A mouse tooth was ground and inserted into a rotor for NMR analysis. The complete tooth was analyzed, which means that the spectra recorded are a reflection of all three components of teeth: dentin, cement, and enamel. Each of these constituents contains apatite. ${ }^{77}$ The fraction of mineral phase is the most important for enamel 
( $>96 \%$ weight), in contrast with cement and dentine, which contains a more significant fraction of organic phase and water.

Figure 10 shows the $1 \mathrm{D}{ }^{1} \mathrm{H}$ and ${ }^{31} \mathrm{P}$ NMR spectra recorded at high magnetic field $(750 \mathrm{MHz}$ spectrometer) and spinning at $50 \mathrm{kHz}$. The single-pulse ${ }^{31} \mathrm{P}$ NMR spectrum presents a single peak at $3.2 \mathrm{ppm}$ [Fig. 10(a)], which corresponds to the phosphate groups of the HA crystallites in teeth. ${ }^{27,28}$ This peak is broader than generally observed for synthetic crystalline HA, in agreement with previous studies, ${ }^{20,22,34}$ meaning that there are different phosphorus local environments in this biological sample. In particular, ${ }^{1} \mathrm{H} \rightarrow{ }^{31} \mathrm{P}$ CPMAS spectra recorded using different contact times show that all phosphates do not have the same ${ }^{1} \mathrm{H}$ environment because the breadth of the peak decreases as the contact time increases. On the basis of previous studies, ${ }^{22}$ such an observation could reflect that not only hydroxyl groups $\left(\mathrm{OH}^{-}\right)$are in close proximity with the phosphates in this sample but also $\mathrm{H}_{2} \mathrm{O}$ molecules or $\mathrm{HPO}_{4}{ }^{2-}$ anions.

The ${ }^{1} \mathrm{H}$ single-pulse spectrum shows several unresolved signals [Fig. 10(b)], and is dominated by the signal centered at $\sim 5 \mathrm{ppm}$ which corresponds mainly to water. The complexity of the ${ }^{1} \mathrm{H}$ NMR spectra arises from the overlapping of contributions from the organic and mineral phases of teeth, and of water. Partial resolution of the peaks can be achieved using the spin-echo sequence, as the different signals have different transverse dephasing times $\mathrm{T}_{2}$. The relative intensity of the water peak dramatically decreases in the spin-echo spectrum, and the signal coming from the hydroxyl groups of the HA crystallites $(\sim 0 \mathrm{ppm})$ appears more distinctly (see Fig. 10). The contribution of the organic component of teeth also becomes more visible. ${ }^{20,23}$ In particular, a broad signal centered at $\sim 8 \mathrm{ppm}$ is clearly observed, which is probably due to the $\mathrm{NH}$ groups of the peptide bonds in collagen. ${ }^{78}$

To gain more information about the distribution in phosphate environments in the mineral phase of the mouse tooth, $2 \mathrm{D}^{1} \mathrm{H}^{3}{ }^{31} \mathrm{P}$ HETCOR ${ }^{20,38}$ spectra were recorded using contact times of $0.3,1$, and $6 \mathrm{~ms}$ (Fig. 11) to look at the relative proximities between protons and phosphorus atoms in the structures. The appearance of the $2 \mathrm{D}$ maps is different, which is not surprising given the differences already observed on the $1 \mathrm{D}{ }^{1} \mathrm{H} \rightarrow{ }^{31} \mathrm{P}$ CPMAS NMR spectra. For the longest contact time [CT $=6 \mathrm{~ms}$; Fig. 11(c)], the most intense cross-peak correlates phosphates with the $\mathrm{OH}^{-}$signal of $\mathrm{HA}$ at $\sim 0 \mathrm{ppm}$. This cross-peak corresponds to a relatively narrow ${ }^{31} \mathrm{P}$ NMR resonance [see Fig. 12(b)], meaning that these phosphates are in a well ordered and relatively crystalline HA environment. Another broader cross-peak correlates the phosphate signal with the $\mathrm{H}_{2} \mathrm{O}$ resonance centered at $\sim 5.5 \mathrm{ppm}$. The proximity between phosphate groups and water molecules is not surprising, given that (i) biological HA crystallites are nanocrystalline and have water molecules at their surface and (ii) structural water is also present as lattice defects within biological HA phases. This cross-peak corresponds to a much broader ${ }^{31} \mathrm{P}$ NMR resonance, as illustrated in Fig. 12(b), confirming that these phosphates are in a more disordered environment. Finally, a broad phosphate signal also correlates with

\section{${ }^{31} P$ MAS NMR}

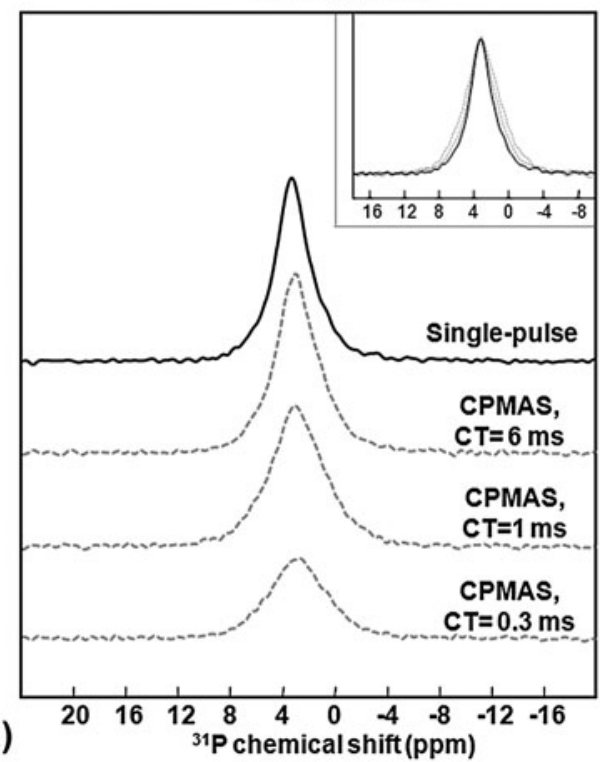

\section{${ }^{1} \mathrm{H}$ MAS NMR}

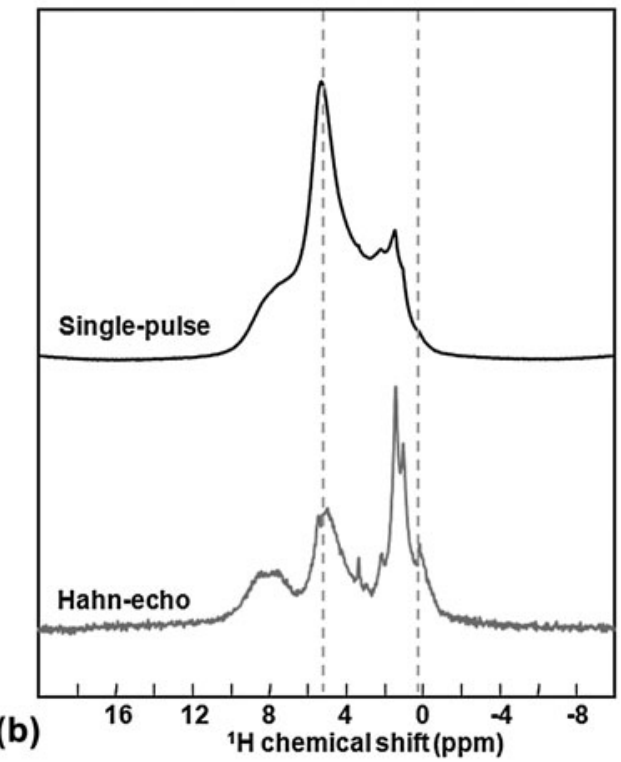

FIG. 10. (a) ${ }^{31} \mathrm{P}$ single-pulse spectrum (in black, top) and ${ }^{1} \mathrm{H} /{ }^{31} \mathrm{P}$ CPMAS spectra (in grey, bottom), recorded with contact times of $0.3,1.0$, and $6.0 \mathrm{~ms}$. The inset at the top right compares the line widths of the single-pulse spectrum with those of the CPMAS spectra recorded with contact times of 1 and 6 ms (the breadth of the phosphate peak varies as indicated in the text). (b) ${ }^{1} \mathrm{H}$ NMR spectra recorded using the single-pulse sequence (in black, top) and the Hahn echo sequence (in grey, bottom). Details on all the acquisition parameters can be found in the experimental section of the manuscript. 
a weaker ${ }^{1} \mathrm{H}$ intensity between $\sim 8$ and $16 \mathrm{ppm}$, which, according to previous studies, ${ }^{20}$ can be assigned to $\mathrm{HPO}_{4}{ }^{2-}$ groups. As it appears on the 2D spectra shown in Figs. 11(a) and 11(b) and in the slices shown in Fig. 12(a), the contribution to the phosphate signal coming from $\mathrm{H}_{2} \mathrm{O}$ and $\mathrm{HPO}_{4}{ }^{2-}$ resonances is more significant when the contact time decreases, to the point that at the shortest contact time, the $\mathrm{OH}^{-}$resonance is not even observed on the $2 \mathrm{D}$ map [Fig. 11(a)]. This explains the changes in lineshape observed on the 1D ${ }^{1} \mathrm{H} \rightarrow{ }^{31} \mathrm{P}$ CPMAS spectra, as the contributions from the less ordered environments increase as the contact times decrease. Studying in detail the CP build up curves for each of these sites may help estimate more accurately the relative proximity of $\mathrm{OH}$ and $\mathrm{H}_{2} \mathrm{O}$ components to the phosphate group. ${ }^{23,25}$

All in all, the experiments carried out here only give a glimpse of the complexity of the structure of a 4-week-old mouse tooth and of the organization of its mineral phase at the atomic scale. Nevertheless, one of the key points to emphasize is that the overall experimental time necessary to carry out all the experiments presented here was only $\sim 14$ h: the ${ }^{1} \mathrm{H}^{31} \mathrm{P}$ HETCOR spectra recorded with contact times of 1 and [Figs. 11(b) and 11(c)] 6 ms only required $3 \mathrm{~h}$ each. Thus, such experiments could be used on a wider range of samples in a time that makes the experiment manageable to help understand the evolution in the mineralization of mice teeth with age or to help determine the role of specific proteins or lipids in their mineralization. It is worth noting that other solid state NMR experiments should also be feasible on these mice teeth to help reach a better description of structure of the mineral phase (and notably the role of other substitutions present in the HA lattice like $\mathrm{CO}_{3}{ }^{2-}$ or $\left.\mathrm{Na}^{+}\right),{ }^{17}$ of the organic matrix, and of the interaction between the organic and mineral phases. ${ }^{26,27}$ In
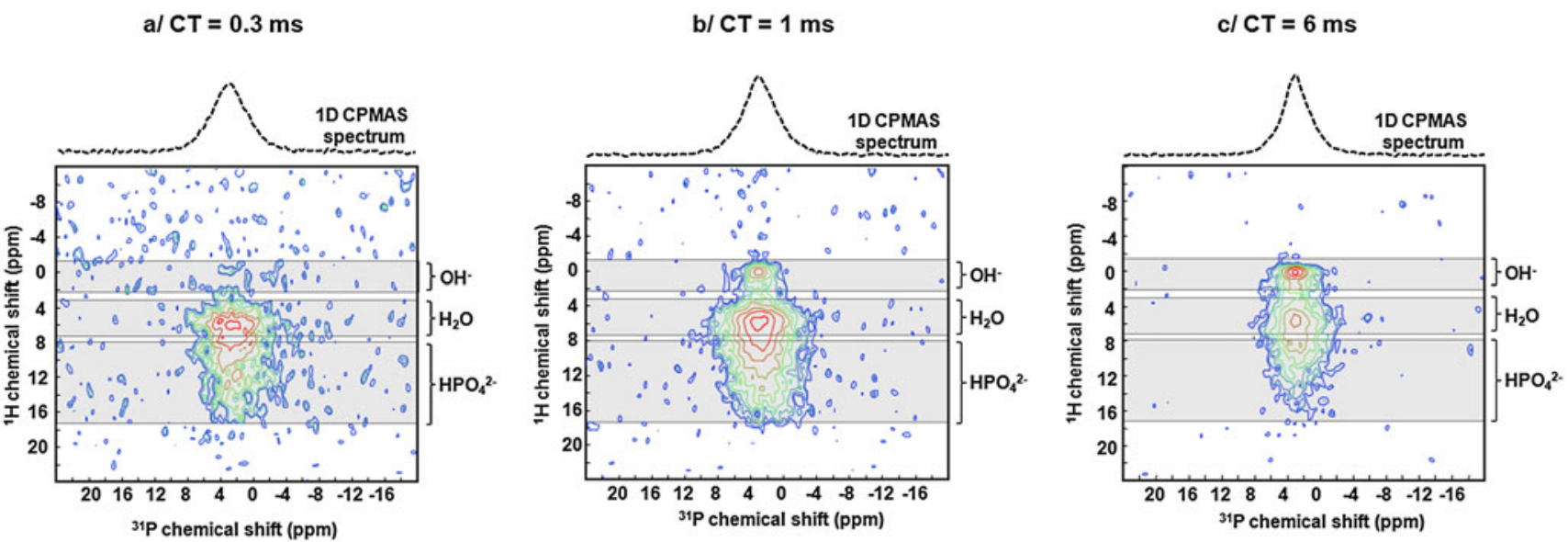

FIG. 11. 2D ${ }^{1} \mathrm{H}_{-}^{31} \mathrm{P}$ HETCOR CPMAS NMR spectra recorded using contact times of $\mathrm{a} / 0.3, \mathrm{~b} / 1.0$, and c/6.0 ms, respectively. HETCOR, heteronuclear-correlation.

$\mathrm{a} / \mathrm{CT}=1 \mathrm{~ms}$

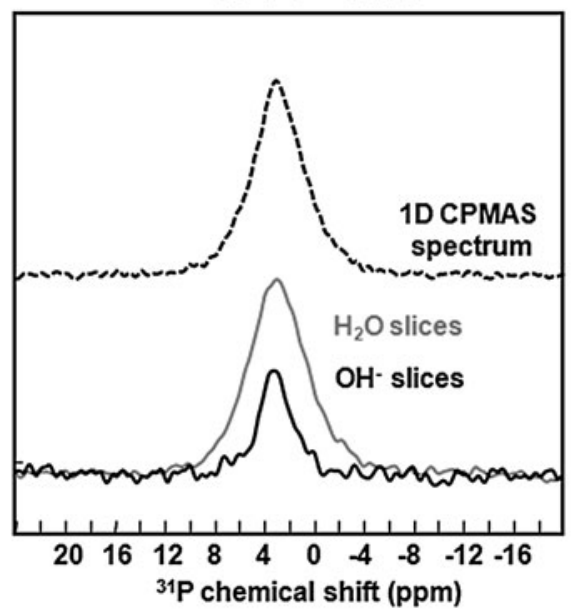

$\mathrm{b} / \mathrm{CT}=6 \mathrm{~ms}$

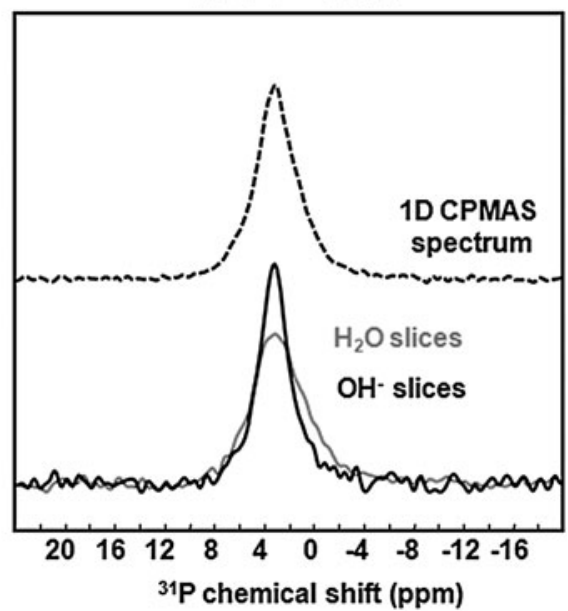

FIG. 12. Top spectra: $1 \mathrm{D}{ }^{1} \mathrm{H} \rightarrow{ }^{31} \mathrm{P}$ CPMAS spectra (recorded with contact times of 1.0 and $6.0 \mathrm{~ms}$ ). Bottom spectra: ${ }^{31} \mathrm{P}$ NMR cross sections of the $2 \mathrm{D}{ }^{1} \mathrm{H}^{-}{ }^{31} \mathrm{P}$ HETCOR spectra, corresponding to the $\mathrm{OH}^{-}$(in black) and $\mathrm{H}_{2} \mathrm{O}$ (in grey) signals. 
particular, it is expected that better resolution of the ${ }^{1} \mathrm{H}$ NMR spectra shown in Fig. 10 should be obtained using a $2 \mathrm{D}{ }^{1} \mathrm{H}^{-}{ }^{1} \mathrm{H}$ FSLG experiment like the one presented for MCPM-monetite. More generally, the methodology presented here may also be applied to other small fractions of biological samples like bone, teeth, or kidney stones, which is particularly important considering the intrinsic structural heterogeneity of these materials.

\section{CONCLUSION}

In this article, high-resolution ${ }^{1} \mathrm{H},{ }^{31} \mathrm{P}$, and ${ }^{17} \mathrm{O}$ solid state NMR experiments have been carried out on synthetic and biological calcium phosphates. In all cases, the importance of performing experiments at high magnetic fields and under fast MAS spinning conditions was shown. Indeed, this allows a significant gain in resolution to be reached, which is particularly important when it comes to trying to understand the NMR spectra of complex materials like mice teeth.

To help in the interpretation of the "basic" single-pulse 1D NMR spectra, a range of more complex 1D and 2D NMR experiments have been presented. For nuclei like oxygen-17, both MQ-MAS sequences and DOR techniques can be particularly useful, the advantage of the latter technique being that ${ }^{1} \mathrm{~J}_{\mathrm{O}-\mathrm{P}}$ couplings can actually be evidenced. Given that ${ }^{1} \mathrm{~J}_{\mathrm{O}-\mathrm{P}}$ couplings had not been reported yet for calcium phosphates, a particular effort was made to try to measure these using also other sequences $\left\{{ }^{31} \mathrm{P}_{-}{ }^{17} \mathrm{O}\right\}$ MAS-HMQC. In the case of spin $-1 / 2$ nuclei like ${ }^{1} \mathrm{H}$ and ${ }^{31} \mathrm{P}$, it was shown that 2D experiments like ${ }^{1} \mathrm{H}-{ }^{1} \mathrm{H}$ FSLG and ${ }^{1} \mathrm{H}_{-}{ }^{31} \mathrm{P}$ HETCOR can be used. In the former case, different isotropic contributions can be extracted, whereas in the latter case information on the local environment of the phosphates can be obtained.

One of the most important points is that by using fast MAS rotors, it is now possible not only to obtain highresolution NMR spectra but also to analyze very small volumes of sample, a fact which turns out to be particularly important when dealing with isotopically enriched (and thus expensive) synthetic materials, or with biological samples. Technological advances such as the development of fast MAS probes are thus of real benefit for the application of NMR to disciplines in which only very small volumes of sample are available. In this context, it is noteworthy that recently developed techniques like Magic Angle Coil Spinning, ${ }^{79,80}$ might also become more common for the characterization of such materials, as even smaller volumes of sample are needed in this case.

\section{ACKNOWLEDGMENTS}

Financial support from the TGIR RMN THC FR3050 for conducting the research is gratefully acknowledged, as well as from CNRS (http://www.tgir-rmn.org/). The Royal Society is acknowledged for a Montpellier-Warwick partnership grant (JP090313), and Engineering and Physical
Sciences Research Council (EPSRC) and the University of Warwick are thanked for partial funding of NMR work at Warwick. DL thanks the 7th European Community Framework Program, which supported this research by a Marie Curie European Reintegration Grant. Calculations were performed on the Institut du Developpement et des Ressources en Informatique Scientifique (IDRIS) supercomputer centre of the CNRS (Project 091461).

\section{REFERENCES}

1. J.C. Elliott: Structure and chemistry of the apatites and other calcium orthophosphates, in Studies in Inorganic Chemistry, Vol. 18 (Elsevier, Amsterdam 1994).

2. S.V. Dorozhkin: Calcium orthophosphates. J. Mater. Sci. 42, 1061 (2007).

3. S.V. Dorozhkin and M. Epple: Biological and medical significance of calcium phosphates. Angew. Chem. Int. Ed. 41, 3130 (2002).

4. S.V. Dorozkhin: Nanosized and nanocrystalline calcium orthophosphates. Acta Biomater. 6, 715 (2010).

5. L. Wang and G.H. Nancollas: Calcium orthophosphates: Crystallization and dissolution. Chem. Rev. 108, 4628 (2008).

6. D. Bazin, C. Chappard, C. Combes, X. Carpentier, S. Rouzière, G. André, G. Matzen, M. Allix, D. Thiaudière, S. Reguer, P. Jungers, and M. Daudon: Diffraction techniques and vibrational spectroscopy opportunities to characterise bones. Osteoporos. Int. 20, 1065 (2009).

7. R.G. Handschin and W.B. Stern: X-ray diffraction studies on the lattice perfection of human bone apatite (Crista iliaca). Bone 16, S355 (1995).

8. C. Rey, C. Combes, C. Drouet, and M.J. Glimcher: Bone mineral: Update on chemical composition and structure. Osteoporos. Int. 20, 1013 (2009).

9. M.A. Rubin, I. Jasiuk, J. Taylor, J. Rubin, T. Ganey, and R.P. Apkarian: TEM analysis of the nanostructure of normal and osteoporotic human trabecular bone. Bone 33, 270 (2003).

10. M.A. Rubin and I. Jasiuk: The TEM characterization of the lamellar structure of osteoporotic human trabecular bone. Micron 36, 653 (2005).

11. L.M. Miller, V. Vairavamurthy, M.R. Chance, R. Mendelsohn, E.P. Paschalis, F. Betts, and A.L. Boskey: In situ analysis of mineral content and crystallinity in bone using infrared microspectroscopy, of the $\mathrm{v}_{4}\left(\mathrm{PO}_{4}\right)_{3}$-vibration. Biochim. Biophys. Acta 1527, 11 (2001).

12. C. Rey, B. Collins, M. Shimizu, and M.J. Glimcher: Resolution enhanced Fourier transform infrared spectroscopic study of the environment of phosphate ion in the early deposits of a solid phase of calcium phosphate in bone and enamel and their evolution with age: I. Investigation in the $\mathrm{v}_{4} \mathrm{PO}_{4}$ domain. Calcif. Tissue Int. 46, 384 (1990).

13. E.P. Paschalis, F. Betts, E. Di Carlo, R. Mendelsohn, and A.L. Boskey: FTIR microspectroscopic analysis of normal human cortical and trabecular bone. Calcif. Tissue Int. 61, 480 (1997).

14. S. Takata, A. Shibata, H. Yonezu, T. Yamada, M. Takahashi, A. Abbaspour, and N. Yasui: Biophysic evaluation of bone qualityapplication of Fourier transform infrared spectroscopy and phosphorus-31 solid-state nuclear-magnetic-resonance spectroscopy. J. Med. Invest. 51, 133 (2004).

15. G. Sauer, W.B. Zunic, J.R. Durig, and R.E. Wuthier: Fourier transform Raman spectroscopy of synthetic and biological calcium phosphates. Calcif. Tissue Int. 54, 414 (1994).

16. C. Rey, C. Combes, C. Drouet, H. Sfihi, and A. Barroug: Physico-chemical properties of nanocrystalline apatites: Implications for biominerals and biomaterials. Mater. Sci. Eng. C27, 198 (2007). 
17. D. Laurencin, A. Wong, W. Chrzanowski, J.C. Knowles, D. Qiu, D.M. Pickup, R.J. Newport, Z. Gan, M.J. Duer, and M.E. Smith: Probing the calcium and sodium local environment in bones and teeth using multinuclear solid state NMR and X-ray absorption spectroscopy. Phys. Chem. Chem. Phys. 12, 1081 (2010).

18. N. Binsted, S.S. Hasnain, and D.W.L. Hukins: Developmental changes in bone mineral structure demonstrated by extended X-ray absorption fine structure (EXAFS) spectroscopy. Biochem. Biophys. Res. Commun. 107, 89 (1982).

19. J.E. Harries, D.W.L. Hukins, and S.S. Hasnain: Calcium environment in bone mineral determined by EXAFS spectroscopy. Calcif. Tissue Int. 43, 250 (1988).

20. W. Kolodziejski: Solid-state NMR studies of bone. Top. Curr. Chem. 246, 235 (2005).

21. F. Pourpoint, C. Gervais, L. Bonhomme-Coury, T. Azaïs, C. Coelho, F. Mauri, B. Alonso, F. Babonneau, and C. Bonhomme: Calcium phosphates and hydroxyapatites: Solid state NMR experiments and first-principles calculations. Appl. Magn. Reson. 32, 435 (2007).

22. S. Maltsev, M.J. Duer, R.C. Murray, and C. Jaeger: A solid-state NMR comparison of the mineral structure in bone from diseased joints in the horse. J. Mater. Sci. 42, 8804 (2007).

23. A. Kaflak-Hachulska, A. Samoson, and W. Kolodziejski: ${ }^{1} \mathrm{H}$ MAS and ${ }^{1} \mathrm{H} \longrightarrow{ }^{31} \mathrm{P}$ CP/MAS NMR Study of Human Bone Mineral. Calcif. Tissue Int. 73, 476 (2003).

24. A. Kaflak and W. Kolodziejski: Complementary information on water and hydroxyl groups in nanocrystalline carbonated hydroxyapatites from TGA, NMR and IR measurements. J. Mol. Struct. 990, 263 (2011).

25. E.E. Wilson, A. Awonusi, M.D. Morris, D.H. Kohn, M.M.J. Tecklenburg, and L.W. Beck: Three structural roles for water in bone observed by solid-state NMR. Biophys. J. 90, 3722 (2006).

26. D.G. Reid, G.J. Jackson, M.J. Duer, and A.L. Rodgers: Apatite in kidney stones is a molecular composite with glycosaminoglycans and proteins: Evidence from nuclear magnetic resonance spectroscopy, and relevance to Randall's plaque, pathogenesis and prophylaxis. J. Urol. 185, 725 (2011).

27. D.G. Reid, M.J. Duer, R.C. Murray, and E.R. Wise: The organic mineral interface in teeth is like that in bone and dominated by polysaccharides: Universal mediators of normal calcium phosphate biomineralization in vertebrates? Chem. Mater. 20, 3549 (2008).

28. S-J. Huang, Y-L. Tsai, Y-L. Lee, C-P. Lin, and J.C.C. Chan: Structural model of rat dentin revisited. Chem. Mater. 21, 2583 (2009).

29. J. Kolmas and W. Kołodziejski: Concentration of hydroxyl groups in dental apatites: A solid-state ${ }^{1} \mathrm{H}$ MAS NMR study using inverse ${ }^{31} \mathrm{P} \longrightarrow>{ }^{1} \mathrm{H}$ cross-polarization. Chem. Commun. 4390 (2007).

30. J.P. Yesinowski and H. Eckert: Hydrogen environments in calcium phosphates: ${ }^{1} \mathrm{H}$ MAS NMR at high spinning speeds. J. Am. Chem. Soc. 109, 6274 (1987).

31. D. Laurencin, A. Wong, R. Dupree, and M.E. Smith: Natural abundance ${ }^{43} \mathrm{Ca}$ solid-state NMR characterization of hydroxyapatite: Identification of the two calcium sites. Magn. Reson. Chem. 46, 347 (2008).

32. C. Gervais, D. Laurencin, A. Wong, F. Pourpoint, J. Labram, B. Woodward, A.P. Howes, K.J. Pike, R. Dupree, F. Mauri, C. Bonhomme, and M.E. Smith: New perspectives on calcium environments in inorganic materials containing calcium-oxygen bonds: A combined computational-experimental ${ }^{43} \mathrm{Ca}$ NMR approach. Chem. Phys. Lett. 464, 42 (2008).

33. W.P. Rothwell, J.S. Waugh, and J.P. Yesinowski: High resolution variable-temperature phosphorus-31 NMR of solid calcium phosphates. J. Am. Chem. Soc. 102, 2637 (1980).

34. J. Kolmas, A. Ślósarczyk, A. Wojtowicz, and W. Kolodziejski: Estimation of the specific surface area of apatites in human mineralized tissues using ${ }^{31} \mathrm{P}$ MAS NMR. Solid State Nucl. Magn. Reson. 32, 53 (2007).
35. G. Cho, Y. Wu, and J.L. Ackerman: Detection of hydroxyl ions in bone mineral by solid-state NMR spectroscopy. Science 300, 1123 (2003).

36. F. Pourpoint, A. Kolassiba, C. Gervais, T. Azaïs, L. BonhommeCoury, C. Bonhomme, and F. Mauri: First-principles calculations of NMR parameters in biocompatible materials science: The case study of calcium phosphates, $\beta$ - and $\gamma-\mathrm{Ca}\left(\mathrm{PO}_{3}\right)_{2}$. Combination with MAS-J experiments. Chem. Mater. 19, 6367 (2007).

37. Y-H. Tseng, C-Y. Mou, and J.C.C. Chan: Solid-state NMR study of the transformation of octacalcium phosphate to hydroxyapatite: A mechanistic model for central dark line formation. J. Am. Chem. Soc. 128, 6909 (2006).

38. C. Jäger, T. Welzel, W. Meyer-Zaika, and M. Epple: A solid-sate NMR investigation of the structure of nanocrystalline hydroxyapatite. Magn. Reson. Chem. 44, 573 (2006).

39. T. Isobe, S. Nakamura, R. Nemoto, M. Senna, and H. Sfihi: Solidstate nuclear magnetic resonance study of the local structure of calcium phosphate nanoparticles synthesized by a wet-mechanochemical reaction. J. Phys. Chem. B. 106, 5169 (2002).

40. D. Laurencin, N. Almora-Barrios, N.H. de Leeuw, C. Gervais, C. Bonhomme, F. Mauri, W. Chrzanowski, J.C. Knowles, R.J. Newport, A. Wong, Z. Gan, and M.E. Smith: Magnesium incorporation into hydroxyapatite. Biomaterials 32, 1826 (2011).

41. S.E. Ashbrook and M.E. Smith: Solid state ${ }^{17} \mathrm{O}$ NMR - an introduction to the background principles and applications to inorganic materials. Chem. Soc. Rev. 35, 718 (2006).

42. K.J.D. MacKenzie and M.E. Smith: Multinuclear Solid State NMR of Inorganic Materials (Pergamon Materials Series, Pergamon Press, Oxford, UK, 2002).

43. G. Wu, D. Rovnyank, B. Sun, and R.G. Griffin: High-resolution multiple quantum MAS NMR spectroscopy of half-integer quadrupolar nuclei. Chem. Phys. Lett. 249, 210 (1995).

44. C.J. Pickard and F. Mauri: All-electron magnetic response pseudopotentials NMR chemical shifts. Phys. Rev. B: Condens.Mater 63, 245101 (2001).

45. H. Chappell, M. Duer, N. Groom, C. Pickard, and P. Bristowe: Probing the surface structure of hydroxyapatite using NMR spectroscopy and first-principles calculations. Phys. Chem. Chem. Phys. 10, 600 (2008).

46. J.P. Amoureux, C. Fernandez, and S. Steuernagel: Z filtering in. MQMAS NMR. J. Magn. Reson. A 123, 116 (1996).

47. B.M. Fung, A.K. Khitrin, and K. Ermolaev: An improved broadband decoupling sequence for liquid crystals and solids. J. Magn. Reson. 142, 97 (2000).

48. C. Coelho, J. Rocha, P.K. Madhu, and L. Mafra: Practical aspects of Lee-Goldburg based CRAMPS techniques for high resolution ${ }^{1} \mathrm{H}$ NMR spectroscopy in solids: Implementation and applications. J. Magn. Reson. 194, 264 (2008).

49. B.J. Van Rossum, H. Förster, and H.J.M. de Groot: High field and high-speed CP MAS ${ }^{13} \mathrm{C}$ NMR heteronuclear dipolar correlation spectroscopy of solids with frequency-switched Lee-Goldburg homonuclear decoupling. J. Magn. Reson. 124, 516 (1997).

50. PARATEC (PARAllel Total Energy Code) by B. Pfrommer, D. Raczkowski, A. Canning, S.G. Louie; Lawrence Berkeley National Laboratory (with contributions from F. Mauri, M. Cote, Y. Yoon, C. Pickard and P. Heynes) based on the GIPAW approach (see Ref. 44); for more information see www.nersc. gov/projects/paratec.

51. J.P. Perdew, K. Burke and M. Ernzerhof: Generalized gradient approximation made simple. Phys. Rev. Lett. 77, 3865 e8 (1996).

52. N. Troulier and J.L. Martins: Efficient pseudopotentials for planewave calculations. 2. Operators for fast iterative diagonalization. Phys. Rev. B 43, 1993 (1991).

53. L. Kleinman and D. Bylander: Efficacious form for model pseudopotentials. Phys. Rev. Lett. 48, 1425 (1982). 
54. L.W. Schroeder, E. Prince, and B. Dickens: Hydrogen bonding in $\mathrm{Ca}\left(\mathrm{H}_{2} \mathrm{PO}_{4}\right)_{2} \cdot \mathrm{H}_{2} \mathrm{O}$ as determined by neutron diffraction. Acta Crystallogr. B B31, 9 (1975).

55. M. Catti, G. Ferraris, and A. Filhol: A hydrogen-bonding in crystalline state: $\mathrm{CaHPO}_{4}$ (Monetite), $P-1$ or $P 1-$ Novel neutrondiffraction study. Acta Crystallogr. B 33, 1223 (1977).

56. M. Profeta, F. Mauri, and C.J. Pickard: Accurate first principles prediction of ${ }^{17} \mathrm{O}$ NMR parameters in $\mathrm{SiO}_{2}$ : Assignment of the zeolite ferrierite spectrum. J. Am. Chem. Soc. 125, 541 (2003)

57. B.R. Cherry, T.M. Alam, C. Click, R.K. Brow, and Z.H. Gan: Combined ab initio computational and solid-state ${ }^{17} \mathrm{O}$ MAS NMR studies of crystalline $\mathrm{P}_{2} \mathrm{O}_{5}$. J. Phys. Chem. B. 107, 4894 (2003).

58. A. Flambard, L. Montagne, and L. Delevoye: A new ${ }^{17} \mathrm{O}$-isotopic enrichment method for the NMR characterisation of phosphate compounds. Chem. Commun. 32, 3426 (2006).

59. C. Gervais, F. Babonneau, and M.E. Smith: Detection, quantification, and magnetic field dependence of solid-state ${ }^{17} \mathrm{O}$ NMR of $\mathrm{X}-\mathrm{O}-\mathrm{Y}(\mathrm{X}, \mathrm{Y}=\mathrm{Si}, \mathrm{Ti})$ linkages: Implications for characterizing amorphous titania-silica-based materials. J. Phys. Chem. B $\mathbf{1 0 5}$, 1971 (2001).

60. C. Gervais, M. Profeta, V. Lafond, C. Bonhomme, T. Azaïs, H. Mutin, C.J. Pickard, F. Mauri, and F. Babonneau: Combined ab initio computational and experimental multinuclear solid-state magnetic resonance study of phenylphosphonic acid. Magn. Reson. Chem. 42, 445 (2004).

61. D. Massiot, F. Fayon, M. Capron, I. King, S. Le Calvé, B. Alonso, J.O. Durand, B. Bujoli, Z. Gan, and G. Hoatson: Modelling one and two-dimensional solid-state NMR spectra. Magn. Reson. Chem. 40, 70 (2002)

62. C. Gervais, R. Dupree, K.J. Pike, C. Bonhomme, M. Profetta, C.J. Pickard, and F. Mauri: Combined first-principles computational and experimental multinuclear solid-state NMR investigation of amino acids. J. Phys. Chem. A 109, 6960 (2005).

63. C. Gervais, M. Profeta, F. Babonneau, C.J. Pickard, and F. Mauri: Ab-initio calculations of NMR parameters of highly coordinated oxygen sites in aluminosilicates. J. Phys. Chem. B 108, 13249 (2004).

64. C. Gervais, C. Coelho, T. Azaïs, J. Maquet, G. Laurent, F. Pourpoint, C. Bonhomme, P. Florian, B. Alonso, G. Guerrero, P.H. Mutin, and F. Mauri: First principles NMR calculations of phenylphosphinic acid $\mathrm{C}_{6} \mathrm{H}_{5} \mathrm{HPO}(\mathrm{OH})$ : Assignments, orientation of tensors by local field experiments and effect of molecular motion. J. Magn. Reson. 187, 131 (2007).

65. L. Frydman and J.S. Harwood: Isotropic spectra of half-integer quadrupolar spins from bidimensional MAS NMR. J. Am. Chem. Soc. 117, 5367 (1995).

66. A. Samoson, E. Lippmaa, and A. Pines: High resolution solid state NMR averaging of second-order effects by means of a double-rotor. Mol. Phys. 65, 1013 (1988).

67. I. Hung, A.P. Howes, B.G. Parkinson, T. Anupold, A. Samoson, S.P. Brown, P.F. Harrison, D. Holland, and R. Dupree: Determi- nation of the bond-angle distribution in vitreous $\mathrm{B}_{2} \mathrm{O}_{3}$ by ${ }^{11} \mathrm{~B}$ double rotation (DOR) NMR spectroscopy. J. Solid State Chem. 182, 2402 (2009).

68. C. Roiland: Etude de l'ordre local dans des phosphates désordonnés modèles par spectroscopies RMN et RAMAN. PhD Thesis (Orléans University, France, 2007).

69. D.L. Bryce, K. Eichele, and R.E. Wasylishen: An ${ }^{17} \mathrm{O}$ NMR and quantum chemical study of monoclinic and orthorhombic polymorphs of triphenylphosphine oxide. Inorg. Chem. 42, 5085 (2003).

70. I. Hung, A. Wong, A.P. Howes, T. Anupõld, J. Past, A. Samoson, X. Mo, G. Wu, M.E. Smith, S.P. Brown, and R. Dupree: Determination of NMR interaction parameters from double rotation NMR. J. Magn. Reson. 188, 246 (2007).

71. C. Bonhomme, C. Gervais, C. Coelho, F. Pourpoint, T. Azaïs, L. Bonhomme-Coury, F. Babonneau, G. Jacob, M. Ferrari, D. Canet, J.R. Yates, C.J. Pickard, S.A. Joyce, and F. Mauri: New perspectives in the PAW/GIPAW approach: $\mathrm{J}_{\mathrm{P}-\mathrm{O}-\mathrm{Si}}$ coupling constants, antisymmetric parts of shift tensors and NQR predictions. Magn. Reson. Chem. 48, S86 (2010).

72. E.M. Menger and W.S. Veeman: Quadrupole effects in highresolution phosphorus-31 solid state NMR spectra of triphenylphosphine copper (I) complexes. J. Magn. Reson. 46, 257 (1982).

73. D. Massiot, F. Fayon, B. Alonso, J. Trebosc, and J.P. Amoureux: Chemical bonding differences evidenced from J-coupling in solid state NMR experiments involving quadrupolar nuclei. J. Magn. Reson. 164, 160 (2003).

74. V. Montouillout, C.M. Morais, A. Douy, F. Fayon, and D. Massiot: Toward a better description of gallo-phosphate materials in solidstate NMR: 1D and 2D correlation studies. Magn. Reson. Chem. 44, 770 (2006).

75. C. Martineau, F. Fayon, C. Legein, J.Y. Buzare, G. Silly, and D. Massiot: Accurate heteronuclear J-coupling measurements in dilute spin systems using the multiple-quantum filtered J-resolved experiment. Chem. Commun. 26, 2720 (2007).

76. A. Lesage: Recent advances in solid-state NMR spectroscopy of spin I = 1/2 nuclei. Phys. Chem. Chem. Phys. 11, 6876 (2009) (and references therein).

77. J.H. Bowes and M.M. Murray: The composition of human enamel and dentine. Biochem. J. 30, 977 (1936).

78. G. Melacini, Y. Feng, and M. Goodman: Acetyl-terminated and template-assembled collagen-based polypeptides composed of Gly-Pro-Hyp sequences. 3. Conformational analysis by ${ }^{1} \mathrm{H}-$ NMR and molecular modeling studies. J. Am. Chem. Soc. 118 10359 (1996).

79. D. Sakellariou, G. Le Goff, and J-F. Jacquinot: High-resolution, high-sensitivity NMR of nanolitre anisotropic samples by coil spinning. Nature 447, 694 (2007).

80. A. Wong, P.M. Aguiar, and D. Sakellariou: Slow magic-angle coil spinning: A high-sensitivity and high-resolution NMR strategy for microscopic biological specimens. Magn. Reson. Med. 63, 269 (2010).

\section{Supplementary Material}

Supplementary materials can be viewed in this issue of the Journal of Materials Research by visiting http://journals.cambridge.org/jmr. 